\title{
Modified Solution Annealing Heat Treatments of Powder Bed Fused Inconel 718
}

\author{
Ala'aldin Alafaghani ( $\nabla$ aalafaghani@ucmerced.edu ) \\ University of California Merced https://orcid.org/0000-0002-2530-3919 \\ Muhammad Ali Ablat \\ UC Merced: University of California Merced \\ Ala Qattawi \\ UT: The University of Toledo
}

\section{Research Article}

Keywords: metal additive manufacturing, design for manufacturing, direct metal laser sintering, heat treatment, mechanical properties, Rietveld refinement, nickel superalloy, microstructure, homogenization, X-ray diffraction

Posted Date: September 27th, 2021

DOI: https://doi.org/10.21203/rs.3.rs-718605/v1

License: (c) (i) This work is licensed under a Creative Commons Attribution 4.0 International License. Read Full License 


\section{Abstract}

Inconel 718 (IN718) is a superalloy commonly used in aerospace, turbomachinery, and applications with extreme conditions due to its creep and corrosion resistance and high strength and hardness at a wide range of temperatures. The recent development of metal additive manufacturing offers a new approach to fabricate complex IN718 parts with minimal machining. However, additively manufactured IN718 parts suffer from anisotropic mechanical properties and are usually inferior to conventionally produced parts. This is especially noticeable under dynamic loading conditions, where they suffer from lower fatigue strength and life in addition to lower reliability. This study focuses on postprocessing heat treatments that aim to homogenize the microstructure of the additively manufactured IN718 and reduce the defects produced during fabrication. In this work, we developed modified solution annealing treatments for IN718 samples, followed by tensile testing. X-ray diffraction and scanning electron microscopy imaging were used to evaluate the microstructure. The results show that by increasing the initial heat treatment temperature, better isotropy, Young's modulus, and ductility were produced at the cost of a slight reduction in the tensile strength. The further rise in the heat treatment temperature increased the grain size significantly and produced unfavourable precipitate morphology, which caused a brittle behaviour.

\section{Introduction}

Inconel 718 (IN718) is a nickel-based superalloy typically used in aerospace and energy applications with extreme operating conditions due to its creep and corrosion resistance [1]. It retains high mechanical properties at low temperatures [2, 3], as well as high temperatures up to $600 \mathrm{C}$ [4]. This unique combination makes it extremely useful in rocket applications where fuels are kept at cryogenic temperatures before combustion and in high-temperature turbomachinery applications. These high mechanical properties, such as the high strength and hardness as well as high creep, wear, and corrosion resistance are attributed to its strengthening precipitates gamma prime and gamma double prime [5]. However, IN718 is not easy to manufacture using conventional methods due to these high mechanical properties. Machining IN718 to produce complex parts or parts with high buy-to-fly ratios is a costly and challenging process due to the high hardness and low heat conductivity of IN718, which could lead to damaging the cutting tool and the workpiece [6-8]. Therefore, machining highly complex IN718 parts is either cost-prohibitive or impossible to produce conventionally. Metal additive manufacturing such as selective laser melting (SLM) and direct metal laser sintering (DMLS) offer an alternative approach to fabricate fully dense parts and near net shape with minimal machining and material waste [9].

However, AM parts have been shown to be inferior to parts manufactured using conventional methods such as forging and casting [10]. They have inferior mechanical properties and suffer from anisotropy [11] due to defects such as porosity, unmolten regions [12,13], and poorly fused layers [14]. These defects, in addition to the residual stresses caused by the high-temperature gradient and non-uniform cooling during fabrication [15], reduce the mechanical loads that additively manufactured parts can handle before failure compared to conventionally manufactured parts [16]. Moreover, fatigue strength and fatigue life are severely reduced $[17,18]$. Previous work in the literature has shown that as-built parts have highly scattered fatigue life even under similar load conditions [19]. In [20], it was shown that optimum tensile strength required a different set of processing parameters than the set required for optimum density. Therefore, it is a challenging task to optimize the processing parameters to reduce all of these defects [21]. The bulk of the literature focuses on optimizing these processing parameters to produce fully or near fully dense parts [22-25]. This shows a need for post-processing treatments to reduce the severity of the defects, residual stresses, unfavourable microstructure, and anisotropy in mechanical properties [26]. 
Heat treatments are standard post-processing routines for IN718 that are designed carefully to maximize the development of the strengthening precipitates $\gamma^{\prime \prime}$ and $\gamma^{\prime}$ while reducing detrimental phases such as the $\delta$ and Laves phases $[27,28]$. The heat treatments should dissolve any phases into the $\gamma$ phase and homogenize the alloying elements. This prevents detrimental phases from stealing the alloying elements from the desirable precipitates. Improper heat treatment can result in transforming $\gamma^{\prime \prime}$ into the $\delta$ phase, which is more thermodynamically stable than $\gamma^{\prime \prime}$ and does not contribute to the strength of the alloy. Most common heat treatments of IN718 start by annealing it at $980-1150^{\circ} \mathrm{C}$, which is above the solvus temperature of the Laves and $\delta$ phases, followed by rapid cooling. Then aging heat treatment takes place at $620-780^{\circ} \mathrm{C}$ to promote the precipitation of $\gamma^{\prime \prime}$ and $\gamma^{\prime}$. The Aerospace Material Specification (AMS) recommended heat treatment is to perform solution annealing at $980^{\circ} \mathrm{C}$ for 1 hour, followed by water quenching. Then age at $720^{\circ} \mathrm{C}$ for 8 hours, furnace cool to $620^{\circ} \mathrm{C}$ and age for another 8 hours followed by air cooling. This heat treatment has been widely investigated for different additive manufacturing methods with IN718 material, such as selective laser melting, selective electron beam melting, direct metal deposition [29, 30]. It was shown, however, that this heat treatment is not successful in producing IN718 AM parts equivalent to conventional parts with similar microstructure [31]. The anisotropy remained with horizontally fabricated specimens being stronger than vertically fabricated specimens, and horizontal specimens remained superior to vertical ones in terms of fatigue life and strength [32] and both being inferior to conventional parts [33,34]. The different microstructures explained the inferior performance developed even after the heat treatment. The small grain sizes and phases developed during fabrication slows the diffusion process required for homogenization.

Research has been done on the effect of modifying the heat treatment by adding a step before the solution annealing or by increasing the solution annealing temperature to improve the homogenization of the additively manufactured parts. In [10, 29, 30, 35-40] different solution annealing temperatures were investigated including 1000, 1065, 1080, $1100,1150,1200$ and $1250^{\circ} \mathrm{C}$. While different durations were investigated in these works, the minimum duration investigated in most of them was one hour. It was found that the standard heat treatment at $980^{\circ} \mathrm{C}$ produced the maximum strength but with a high dependency on the orientation. The high strength gained, however, was at the cost of the ductility as the standard heat treatment showed the lowest ductility among the different solution annealing heat treatments. Furthermore, it is difficult to eliminate the Laves phase, which is usually detrimental to the mechanical properties, completely using the standard heat treatment [41]. Direct aging from as-built condition resulted in a reduced amount of the strengthening phases precipitating [42]. Solution annealing or homogenising at higher temperatures, especially close to $1200^{\circ} \mathrm{C}$ recovered some of the ductility shown by the as-built condition. Furthermore, the influence of anisotropy was reduced. However, the gain in ductility came at the price of reduced strength. The microstructure coarsening to double or two and a half times and the reduced amounts of $y^{\prime}$ and $\gamma^{\prime \prime}[35,38]$ were used to explain this reduction of strength. Also, it was shown that recrystallization occurs at $1180^{\circ} \mathrm{C}$ [43]. Annealing or homogenization at $1227^{\circ} \mathrm{C}$ was found to reduce the residual stresses the most [44]. Hot isostatic pressure (HIP) heat treatments were investigated in $[36,45-47]$. Pressures of $100-150 \mathrm{MPa}$ and temperatures of $1150-1200^{\circ} \mathrm{C}$ were the most common in literature as recommended by the ASTM F3055 standard [48]. HIP was found to reduce the porosity; however, some pores remained even after HIP. Slight improvement in the ductility with some reduction in strength was shown after applying HIP heat treatments. It was reported that HIP heat treatments followed directly by aging reduce the amount of $Y^{\prime \prime}$ precipitating, in addition to significant grain size growth, which explains the reduction in strength and hardness. In a preliminary study it was shown that different microstructure characterises developed in different metal additive manufacturing technologies persist to be different even after similar heat treatments [49]. Different aging heat treatments were investigated in $[35,37,43]$, which showed that increasing the time or temperature of the aging heat treatment generally results in increasing the size of the $\gamma^{\prime \prime}$ precipitates. Direct aging by controlling the cooling rate from the solution annealing temperatures to pass through the $\gamma^{\prime}$ and $\gamma^{\prime \prime}$ regions in the continuous cooling transformation (CCT) diagram, while avoiding the $\delta$ region, was investigated in [50]. While the presence of the $\gamma^{\prime \prime}$ precipitates was 
confirmed using transmission electron microscopy, the performance of the in-situ aged tensile specimens was very poor compared to the control specimens.

In this work, additively manufactured IN718 specimens are heat-treated using different solution annealing heat treatments at higher temperatures than the standard heat treatment. This heat treatment step is held for a short time up to 20 minutes, followed by furnace cooling to the standard annealing temperature. Then the specimens are held there for another 20-40 minutes since it was shown that the standard heat treatment temperature improves the precipitation of $\mathrm{y}^{\prime \prime}$ during aging. After that, the specimens are water quenched and then aged using the standard aging heat treatment. The goal is to homogenize the microstructure to reduce the influence of building orientation, dissolve the unfavourable $\delta$, and laves phases while preventing extensive grain size growth. The purpose of the homogenization is to reduce the influence of the building orientation. This can reduce design and manufacturing considerations [51] required due to the limited orientations the part can be fabricated without requiring supports or increasing the residual stresses. Thus, a part can be fabricated in the most feasible orientation without worrying about the resulting mechanical properties, which can be improved by suitable heat treatment. Quantitative X-ray diffraction using Rietveld refinement was used to estimate the volume fraction of the precipitates to aid in explaining the resulting mechanical properties. The refinement was aided using scanning electron microscopy images, to confirm the validity of the refinement. The additively manufactured IN718 specimens used in this work were fabricated using DMLS, which is a laser-based powder bed fusion additive manufacturing method. The laser fuses the powder on the bed according to the sliced 3D CAD model. After each finished layer, the powder bed falls to allow the deposition of a new powder layer on top of the previous one. The new layer is then scanned and melted according to the next slice of the model. Figure 1 shows a schematic of the DMLS process.

\section{Materials And Methods}

\section{Testing plan}

Two heat treatments are proposed and compared to the as-built condition and the standard heat treatment as described by AMS 5663. The as-built condition is labelled HTO in this work. The standard heat treatment holds the alloy at $980^{\circ} \mathrm{C} \pm 14^{\circ} \mathrm{C}$ for one hour followed by water quenching and is labelled as HT1 in this work. The first proposed heat treatment includes a homogenization step prior to the solution annealing. It is done by holding the specimens at $1200^{\circ} \mathrm{C}$ for 20 minutes, then furnace cooling to $980^{\circ} \mathrm{C}$ and holding there for 20 minutes before water quenching. This heat treatment is labelled HT2. The second proposed heat treatment included homogenizing the specimens at $1270^{\circ} \mathrm{C}$ for 5 minutes, then furnace cooling to $980^{\circ} \mathrm{C}$ and holding at $980^{\circ} \mathrm{C}$ for 40 minutes before water quenching. This heat

treatment is labelled HT3. All performed heat treatments were then followed by standard aging heat treatment, as described by the AMS 5663 standard, at $720^{\circ} \mathrm{C}$ for 8 hours, then furnaced cooled to $620^{\circ} \mathrm{C}$ in 2 hours and held at that temperature for another 8 hours, followed by air cooling. For each of the four heat treatment conditions, samples were prepared in three different orientations, the $X Y Z$ orientation, the $Y Z X$ orientation, and the $Z X Y$, as described in the ASTM-F2971-13 standard [52], and abbreviated in this work as X, Y, and Z, respectively. Figure 2 illustrates the orientations of the samples. Table 1 lists the batch number, the assigned building direction, the heat treatments, and the number of tested specimens for each batch. The experiment plan follows a full factorial design of experiments to determine the number of samples by investigating all combinations of heat treatments and build orientations. The goal of the testing plan is to capture the influence of the different solution annealing treatments on the samples' mechanical properties, anisotropy, and microstructure.

\section{Specimens Preparation}


All the IN718 specimens were fabricated on the EOSINT M 290 system using the commercialized powder IN718. Table 2 lists the weight percentage, supplied by the vendor, of the chemical composition of the raw powder we used for fabricating the DMLS IN718 specimens. Table 3 lists the processing parameters used during the additive manufacturing of the specimens, such as the laser power, scanning speed, hatch distance, layer thickness, etc. The specimens were fabricated according to the ASTM-E8/E8M [53] subsize specimen with dimensions, as shown in Fig. 3.

Table 1

Sample specifications

\begin{tabular}{|c|c|c|c|c|}
\hline $\begin{array}{l}\text { Batch } \\
\text { No. }\end{array}$ & Heat Treatment & $\begin{array}{l}\text { Build } \\
\text { Direction }\end{array}$ & $\begin{array}{l}\text { Heat treatment name and } \\
\text { direction }\end{array}$ & Replicas \\
\hline 1 & As-built & $(X)$ & HTO X & 3 \\
\hline 2 & As-built & $(\mathrm{Y})$ & HTO Y & 3 \\
\hline 3 & As-built & $(Z)$ & HTO Z & 3 \\
\hline 4 & $980^{\circ} \mathrm{C}$ for $1 \mathrm{hr}$ then WQ & $(X)$ & HT1 X & 3 \\
\hline 5 & $980^{\circ} \mathrm{C}$ for $1 \mathrm{hr}$ then WQ & $(\mathrm{Y})$ & HT1 Y & 3 \\
\hline 6 & $980^{\circ} \mathrm{C}$ for $1 \mathrm{hr}$ then WQ & $(Z)$ & HT1 Z & 3 \\
\hline 7 & $\begin{array}{l}1200^{\circ} \mathrm{C} \text { for } 20 \text { min } \mathrm{FC} \text { to } 980^{\circ} \mathrm{C} \text { and hold for } 20 \\
\text { min then WQ }\end{array}$ & $(X)$ & HT2 X & 3 \\
\hline 8 & $\begin{array}{l}1200^{\circ} \mathrm{C} \text { for } 20 \text { min } \mathrm{FC} \text { to } 980^{\circ} \mathrm{C} \text { and hold for } 20 \\
\text { min then WQ }\end{array}$ & $(Y)$ & HT2 Y & 3 \\
\hline 9 & $\begin{array}{l}1200^{\circ} \mathrm{C} \text { for } 20 \text { min } \mathrm{FC} \text { to } 980^{\circ} \mathrm{C} \text { and hold for } 20 \\
\text { min then WQ }\end{array}$ & $(Z)$ & HT2 Z & 3 \\
\hline 10 & $\begin{array}{l}1270^{\circ} \mathrm{C} \text { for } 5 \text { min } W Q \text { then } 980^{\circ} \mathrm{C} \text { for } 40 \mathrm{~min} \\
\text { then WQ }\end{array}$ & $(X)$ & HT3 X & 3 \\
\hline 11 & $\begin{array}{l}1270^{\circ} \mathrm{C} \text { for } 5 \text { min } W Q \text { then } 980^{\circ} \mathrm{C} \text { for } 40 \text { min } \\
\text { then WQ }\end{array}$ & $(Y)$ & HT3 Y & 3 \\
\hline 12 & $\begin{array}{l}1270^{\circ} \mathrm{C} \text { for } 5 \mathrm{~min} W Q \text { then } 980^{\circ} \mathrm{C} \text { for } 40 \mathrm{~min} \\
\text { then WQ }\end{array}$ & $(Z)$ & HT3 Z & 3 \\
\hline
\end{tabular}

Table 2

Raw powder chemical composition in weight percentage of the IN718 DMLS Samples

\begin{tabular}{|lllllllllllllll|}
\hline IN718 & Ni & Cr & Nb & Mo & Ti & Al & Co & Cu & C & Si, & P, S & B & Fe \\
& & & & & & & & & & Mn & & & \\
& $50-$ & $17.0-$ & $4.75-$ & $2.8-$ & $0.65-$ & $0.20-$ & 1.0 & 0.3 & 0.08 & 0.35 & 0.015 & 0.006 & Bal \\
& 55 & 21.0 & 5.5 & 3.3 & 1.15 & 0.80 & max & max & max & max & max & max & \\
\hline
\end{tabular}

Table 3

DMLS processing parameters used to fabricate the samples

\begin{tabular}{|llllllll|}
\hline Metal & System & $\begin{array}{l}\text { Laser } \\
\text { Power }\end{array}$ & $\begin{array}{l}\text { Laser } \\
\text { Diameter }\end{array}$ & $\begin{array}{l}\text { Hatch } \\
\text { Distance }\end{array}$ & Scan Style & $\begin{array}{l}\text { Layer } \\
\text { Thickness }\end{array}$ & $\begin{array}{l}\text { Inert } \\
\text { Gas }\end{array}$ \\
\hline IN718 & M 290 & $400 \mathrm{~W}$ & $\begin{array}{l}100 \\
\text { microns }\end{array}$ & $\begin{array}{l}150 \\
\text { microns }\end{array}$ & $\begin{array}{l}\text { Alternating Stripes with } 67^{\circ} \\
\text { rotation }\end{array}$ & 40 microns & Ar \\
\hline
\end{tabular}

Mechanical Properties Test 
To evaluate the mechanical properties of the DMLS fabricated samples of IN718, the authors performed tensile tests on the heat-treated and as-built specimens using an Instron universal testing machine 3369, with a load cell of $50 \mathrm{kN}$. We carried the test according to the ASTM E8/E8M standard for axial tension tests of metallic specimens. The testing speed was controlled by an extension rate of $0.48 \mathrm{~mm} / \mathrm{min}$, which should maintain a strain rate of $0.015 / \mathrm{min}$ in the region before yield in the stress-strain diagram per the ASTM E8/E8M standard. The data collected were time, extension, load, and the strain recorded by an extensometer with a $25 \mathrm{~mm}$ gauge length. In addition, a Digital Image Correlation (DIC) system was used during the testing to evaluate Poisson's ratio and observe the breaking patterns and the strain fields associated with them. The DIC system used in this study utilizes two digital cameras that observe the same spot from two different angles, therefore forming a 3D surface of the tested specimens, as can be seen in Fig. 4 . The specimens were painted with white and black patterns to aid the system in measuring the strains as the tensile test progresses. Strains in the vertical $(Y)$ and horizontal $(X)$ directions are measured by tracking the changes in the distances between points aligned in those directions. Three distances are assigned for the $\mathrm{X}$ directions to improve the quality of the measurements in this direction due to the smaller dimensions associated with these directions as can be seen in Fig. 4.

\section{Imaging Analysis}

Fractography images of the broken specimens' surfaces were taken using scanning electron microscopy (SEM) to observe the fracture patterns and the presence of porosity and unmolten powder at the surface of the fracture. The microstructure of the as-built and heat-treated specimens were investigated to observe the grain patterns, grain sizes, and the presence of precipitates. The SEM images were taken using a field emission gun SEM-Gemini 500, with Everhart-Thornley secondary electron detector. An acceleration voltage of $3.0 \mathrm{kV}$ for all the images with a working distance of 3.0-5.5 mm for the microstructure images and 9.4-16.1 $\mathrm{mm}$ for the fractography images.

The microstructure analysis was done on regions on the specimen's grip section to avoid strain hardening effects on the microstructure. The specimens were cut and mounted in epoxy sample holders at room temperature to avoid further exposure to elevated temperature. Then specimens were polished with silicon carbide paper with grit 120 and increased gradually to 1200 . Much care was taken not to overheat the samples. Then they were polished using diamond suspensions with particle sizes 1 micron followed by a suspension with particle sizes of 0.25 microns.

Waterless Kalling's reagent $\left(2 \mathrm{~g} \mathrm{CuCl}_{2}+40 \mathrm{ml} \mathrm{HCl}+40 \mathrm{ml}\right.$ methanol) was used to reveal the microstructure. The etchant was applied by swapping for a few seconds up to a minute and then rinsed with deionized water and isopropanol. The imaging was done on a plane normal to the tensile stress.

\section{X-ray diffraction analysis}

Quantitative phase analysis was carried out to aid in explaining the differences in the tensile strength corresponding to different heat treatments. The XRD analysis was done on mirror polished sections of the flat side of the grips of the tensile specimens. The data was collected using PANalytical X'Pert PRO Theta Diffraction system, using a step size $0.002^{\circ}$, and a dwelling time of $0.12 \mathrm{~s}$ per step, starting from $2 \theta=20-130^{\circ}$ with Cobalt target anode of wavelength $1.789 \mathrm{~A}^{\circ}$. To improve the quality of the spectra, $1 / 4^{\circ}$ anti-scatter slits were used. The irradiated specimens were rotated to reduce the effect of preferred orientation. Crystal information files from the inorganic crystal structure database (ICSD) and crystallography open database (COD) were adapted as initial data for the quantitative Rietveld refinement. The analysis included the matrix phase $\gamma$, the main strengthening precipitates $\gamma^{\prime}$ and $\gamma^{\prime \prime}$, in addition to the $\delta$ phase precipitates and Laves phase. Table 4 lists the initial crystal information of the phases included in the analysis, such as the space group, lattice parameters, and atom positions. Using a predetermined background noise signal, the refinement protocol starts by refining the scale factor, the sample displacement, then the Caglioti coefficients $\mathrm{W}, \mathrm{V}$, and $\mathrm{U}$, and finally, the preferred orientation. The refinement of the lattice parameters was avoided because of the significant 
number of phases and parameters required for the refinement. Performing the refinement with that many parameters will reduce the probability of convergence or produce non-physical values. Moreover, the lattice parameters used closely match refined data in the literature for IN718 phase quantification, and while the lattice might change due to the different solution heat treatments, the resulting change is marginal [54, 55].

\section{Results And Discussion}

\section{Mechanical Properties Test Results}

The results of the tensile tests are summarized in Table 5, which lists Young's modulus, yield strength, tensile strength, ductility, and Poisson's ratio. These properties were calculated according to each specimens' individual dimensions to avoid variations caused by dimensional errors of the additively manufactured specimens. The influence of the proposed different solution annealing heat treatments on the mechanical properties of DMLS IN718 is better illustrated in Fig. 5. It shows the relationship between the samples' building orientation and the mechanical properties of as-built specimens (HTO), HT1, HT2, and HT3 heat-treated specimens. Each point showed in the figures is located using the average of the three repeated samples for each testing specimen listed in Table 1.

Table 4

Crystal information of the phases included in the quantitative XRD analysis

\begin{tabular}{|c|c|c|c|c|c|c|}
\hline Phase & Space group & Lattice $\left[\mathrm{A}^{\circ}\right]$ & Atom & Location & Partial occupancy & Reference code \\
\hline \multirow[t]{3}{*}{ Y } & Fm-3m & $a=3.598$ & $\mathrm{Ni}$ & $(0,0,0)$ & 0.50 & 10219-ICSD \\
\hline & & & $\mathrm{Cr}$ & $(0,0,0)$ & 0.30 & \\
\hline & & & $\mathrm{Fe}$ & $(0,0,0)$ & 0.20 & \\
\hline \multirow[t]{3}{*}{$Y^{\prime}$} & Pm-3m & $a=3.57$ & $\mathrm{Ni}$ & $(0,0.5,0.5)$ & 1.0 & 58039-ICSD \\
\hline & & & $\mathrm{Al}$ & $(0,0,0)$ & 0.63 & \\
\hline & & & $\mathrm{Ti}$ & $(0,0,0)$ & 0.37 & \\
\hline \multirow[t]{3}{*}{$\gamma^{\prime \prime}$} & $14 / \mathrm{mmm}$ & $a=3.62$ & $\mathrm{Nb}$ & $(0,0,0)$ & 1.0 & 105175-ICSD \\
\hline & & $c=7.41$ & $\mathrm{Ni1}$ & $(0,0,0.5)$ & 1.0 & \\
\hline & & & $\mathrm{Ni} 2$ & $(0,0.5,0.5)$ & 1.0 & \\
\hline \multirow[t]{3}{*}{$\delta$} & Pmmn & $a=4.25$ & $\mathrm{Nb}$ & $(0.25,1.75,0.167)$ & 1.0 & COD-1522733 \\
\hline & & $b=5.11$ & $\mathrm{Ni1}$ & $(0.25,0.25,0.167)$ & 1.0 & \\
\hline & & $c=4.54$ & $\mathrm{Ni} 2$ & $(0.25,0,0.667)$ & 1.0 & \\
\hline \multirow[t]{3}{*}{ Laves } & $\mathrm{P}_{3} \mathrm{mmc}$ & $a=4.796$ & $\mathrm{Nb}$ & $(0.333,0.666,0.563)$ & 1.0 & 198050-ICSD \\
\hline & & $c=15.666$ & Fe1 & $(0.17,0.34,0.25)$ & 1.0 & \\
\hline & & & $\mathrm{Fe} 2$ & $(0,0,0)$ & 1.0 & \\
\hline
\end{tabular}


Table 5

Mechanical properties test results for DMLS samples of IN718 materials

\begin{tabular}{|c|c|c|c|c|c|}
\hline Condition / orientation & Modulus [GPa] & Yield [MPa] & Tensile Strength [MPa] & Ductility [mm/mm] & Vxy \\
\hline HTO X-1 & 161.3 & 713.2 & 1039.2 & 39.01 & 0.31 \\
\hline HTO X-2 & 138.5 & 696.0 & 1022.1 & 27.84 & 0.32 \\
\hline HTO X-3 & 141.1 & 727.2 & 1040.1 & 28.96 & 0.30 \\
\hline НTO Y-1 & 164.8 & 665.7 & 991.5 & 27.32 & 0.41 \\
\hline HTO Y-2 & 128.7 & 654.5 & 976.0 & 27.79 & 0.43 \\
\hline НTO Y-3 & 114.1 & 647.1 & 1005.5 & 27.05 & 0.39 \\
\hline HTO Z-1 & 102.5 & 580.0 & 882.9 & 30.97 & 0.37 \\
\hline НTO Z-2 & 83.1 & 615.6 & 930.4 & 33.63 & 0.36 \\
\hline HTO Z-3 & 84.9 & 629.3 & 948.3 & 34.41 & 0.39 \\
\hline HT1 X-1 & 184.8 & 1208.3 & 1433.1 & 13.74 & 0.25 \\
\hline HT1 X-2 & 186.4 & 1214.8 & 1444.8 & 14.14 & 0.25 \\
\hline HT1 X-3 & 186.8 & 1216.4 & 1445.1 & 13.48 & 0.30 \\
\hline HT1 Y-1 & 179.0 & 1150.5 & 1361.9 & 9.07 & 0.27 \\
\hline HT1 Y-2 & 185.5 & 1162.5 & 1372.3 & 8.48 & 0.37 \\
\hline HT1 Y-3 & 182.5 & 1154.1 & 1369.0 & 8.86 & 0.34 \\
\hline HT1 Z-1 & 174.3 & 1114.5 & 1346.7 & 14.61 & 0.34 \\
\hline HT1 Z-2 & 169.1 & 1102.1 & 1319.2 & 14.53 & 0.37 \\
\hline HT1 Z-3 & 168.9 & 1102.0 & 1329.0 & 14.33 & 0.36 \\
\hline HT2 X-1 & 189.8 & 949.2 & 1203.0 & 18.08 & 0.31 \\
\hline HT2 X-2 & 196.1 & 945.2 & 1207.6 & 19.17 & 0.32 \\
\hline HT2 X-3 & 191.4 & 1014.8 & 1248.5 & 20.00 & 0.25 \\
\hline HT2 Y-1 & 187.6 & 940.6 & 1182.2 & 19.24 & 0.29 \\
\hline HT2 Y-2 & 193.6 & 960.0 & 1188.6 & 16.45 & 0.34 \\
\hline HT2 Y-3 & 187.2 & 979.3 & 1193.8 & 16.10 & 0.31 \\
\hline HT2 Z-1 & 174.6 & 908.7 & 1146.8 & 19.49 & 0.31 \\
\hline HT2 Z-2 & 174.4 & 908.5 & 1125.5 & 14.56 & 0.34 \\
\hline HT2 Z-3 & 180.3 & 980.4 & 1192.1 & 16.07 & 0.32 \\
\hline HT3 X-1 & 189.2 & 1060.3 & 1261.0 & 12.09 & 0.32 \\
\hline HT3 X-2 & 186.0 & 1055.8 & 1252.7 & 11.84 & 0.31 \\
\hline HT3 X-3 & 186.5 & 1050.2 & 1255.6 & 11.95 & 0.31 \\
\hline
\end{tabular}




\begin{tabular}{|llllll|}
\hline Condition / orientation & Modulus [GPa] & Yield [MPa] & Tensile Strength [MPa] & Ductility [mm/mm] & Vxy \\
\hline HT3 Y-1 & 179.0 & 965.7 & 1183.2 & 9.98 & 0.37 \\
\hline HT3 Y-2 & 173.1 & 956.4 & 1188.0 & 10.18 & 0.36 \\
\hline HT3 Y-3 & 175.5 & 959.9 & 1180.1 & 10.11 & 0.39 \\
\hline HT3 Z-1 & 170.9 & 1044.8 & 1213.7 & 11.40 & 0.40 \\
\hline HT3 Z-2 & 169.3 & 1035.2 & 1201.3 & 11.51 & 0.38 \\
\hline HT3 Z-3 & 171.2 & 1039.1 & 1211.4 & 11.55 & 0.36 \\
\hline
\end{tabular}

Figure 5 shows that Young's modulus, the yield strength, the tensile strength, the ductility, and Poisson's ratio of the DMLS IN718 specimens are highly affected by the heat treatment scheme. Generally, all the mechanical properties increased after the solution annealing heat treatments and the aging except for the ductility. In Fig. 5(a) it can be seen that all the solution heat treatments resulted in a significant increase in Young's modulus for all orientations, especially the Z-built specimens, which were significantly lower in the as-built condition (HT0). HT1 resulted in the second-highest modulus for all orientations with HT2 being the highest. HT3 had the third-highest modulus. HTO had the lowest modulus of elasticity with more than $40 \mathrm{GPa}$ difference compared to the solution annealed specimens. In terms of solution annealed specimens, they all had lower variations in their Young's modulus among the different orientations compared to the as-built condition. It is noticed that the Z-built specimens had significantly lower modulus than the $\mathrm{X}$ and Y-built specimens with a difference of around $50 \mathrm{GPa}$, as well. In comparison, the difference in Young's modulus for the solution annealed specimens among different orientations was up to $15 \mathrm{GPa}$.

Results show that the yield strength increased significantly after the solution annealing heat treatments. HT1 showed the highest increase in yield strength with $500 \mathrm{MPa}$ on average, followed by HT3, then HT2 with over $300 \mathrm{MPa}$ increase compared to HTO, as can be seen in Fig. 5(b). Similarly, the tensile strength increased after the heat treatments, which can be illustrated in Fig. 5(c). The increase in the tensile strength value, however, is less than the one in the yield strength with around $400 \mathrm{MPa}$ for HT1 and $160 \mathrm{MPa}$ for HT2 and HT3. The difference among different orientations for HTO, HT1, HT3 was about 100 MPa for the tensile and yield strengths and about 50 MPa for HT2. It should be noted that while the difference between the $X$ and $Y$-built specimens is much smaller compared to the difference between them and the Z-built specimens, the X-built specimens had higher stiffness and strength than Y-built specimens in every condition.

The ductility of the heat-treated specimens was significantly lower than the as-built specimens, as can be seen in Fig. 5(d). HT1 and HT3 had the lowest ductility with strains ranging between $10-15 \%$ at fracture, while HTO had the maximum ductility with strains ranging between $27-32 \%$. HT2 had the highest ductility among the solution annealed specimens with strains ranging between 16.5-19.0\% at fracture. Moreover, we can see that the Z-built specimens have the highest ductility in the ah-built condition and HT1 with the X-built specimens a close second and Y-built specimens showing the lowest ductility. In HT2 and HT3, the variation in the ductility of specimens fabricated in different orientations is reduced, and the X-built specimens having slightly higher ductility in both HT2 and HT3.

The influence of the heat treatments on Poisson's ratio $v x y=-d \varepsilon x / d \varepsilon y$ is presented in Fig. 5(e). It can be seen that Poisson's ratio for the heat-treated specimens was generally higher than the as-built specimens. In addition, we can see that Poisson's ratio is generally lower for the X-built specimens and that the difference among the different orientations is minimum for HT2, which suggests improved isotropy.

Figure 6-Fig. 9 shows the strain fields of tensile specimens just before the fracture. From Fig. 6 we can see that as-built specimens suffered from high strains before failing. The effect of necking is clear with high strains in the necking area 
going up to $40 \%$ in addition to a large portion of the specimen enduring $20-25 \%$ strain, as can be seen from the histograms. HT1 specimens were able to hold significantly less strain before failing, and significantly less necking occurred before fracture, as can be seen from Fig. 7. The strain around the necking area dropped to less than $20 \%$ for both $X$ and Z-built specimens and about $10 \%$ for the Y-built specimens, these results reflect the ductility results in Fig. 5(d). Also, the strain seems to be more uniformly distributed along the length of the specimens.

HT2 specimens seem to have recovered some of their ductility around $23-29 \%$, and slight necking can be observed in Fig. 8, with more strain concentrated around the failure area. From Fig. 9 we can see that HT3 strain around the necking area had slightly higher values than $\mathrm{HT} 1$, but with less uniform strain distributed along the length of the specimens.

To evaluate the influence of the different solution annealing heat treatments on the anisotropy and repeatability of additively manufactured IN718, an anisotropy index $\left(\sigma_{A}\right)$ is proposed. The anisotropy index $\left(\sigma_{A}\right)$ is calculated by taking the standard deviation of the averaged property values for each orientation for a specific heat treatment which means it only calculates the variations of the averaged value for the $\mathrm{X}$ orientation, $\mathrm{Y}$ orientation, and $\mathrm{Z}$ orientation, which are the bar values shown in Fig. 5, without the error bars. The values for $\sigma_{A}$ are summarized in Table 6 . The $\sigma_{A}$ values indicate that HT2 has the lowest variations in the mechanical properties of specimen fabricated in different orientations for all the mechanical properties except for Young's modulus, where it was a close second after HT1, and for the ductility, where HT2 was a close second after HT3. A similar observation can be made by calculating the standard deviation for all specimens belonging to a specific heat treatment, without averaging them for each orientation before taking their standard deviation. This indicates that HT2 has the lowest anisotropy resulting from manufacturing the specimens in different orientations. In addition to that, HT2 has the highest reliability as the standard deviations for all of the specimens belonging to HT2 showed the lowest variations in their mechanical properties overall.

Table 6

Standard deviation of the resulting mechanical properties for different heat treatments

\begin{tabular}{|llllll|}
\hline Heat Treatment & Young's Modulus & Yield Strength & Tensile Strength & Ductility & Vxy \\
\cline { 2 - 6 } & $\sigma_{\mathrm{A}}[\mathrm{GPa}]$ & $\sigma_{\mathrm{A}}[\mathrm{MPa}]$ & $\sigma_{\mathrm{A}}[\mathrm{MPa}]$ & $\sigma_{\mathrm{A}}[\mathrm{mm} / \mathrm{mm}]$ & $\sigma_{\mathrm{A}}[\mathrm{d} \varepsilon \mathrm{x} / \mathrm{d} \varepsilon \mathrm{y}]$ \\
\hline HT0 & \pm 29.87 & \pm 54.26 & \pm 58.88 & \pm 0.026 & \pm 0.052 \\
HT1 & \pm 7.93 & \pm 53.54 & \pm 55.74 & \pm 0.031 & \pm 0.046 \\
\hline HT2 & \pm 8.53 & \pm 19.26 & \pm 32.48 & \pm 0.012 & \pm 0.015 \\
HT3 & \pm 8.89 & \pm 51.59 & \pm 36.50 & \pm 0.010 & \pm 0.037 \\
\hline
\end{tabular}

\section{SEM Fractography}

The fractured surfaces of the IN718 specimens are presented in Fig. 10-Fig. 13. From Fig. 10 we can see that the topography of as-built specimens is very prominent and rise high from the surface. Additionally, from the high magnification images in Fig. 10 (b,d), we can see clear topography. This indicates a ductile fracture mode. No clear distinction in the high magnification fractography can be discerned of the as-built condition of different orientations.

For the HT1 and HT2 heat-treated specimens, the fractured surfaces were mostly flat in the center but had high changes in topography at the edges, as can be seen in Fig. 11(a,c) and Fig. 12(a,c). However, the lips of the HT2 specimens are thicker, describing more ductile fracture than HT1 specimens. The topography observed in the high magnification images of HT1 is more similar to the ones observed in the as-built specimens than in HT2. The HT2 
topography in the high magnification images shows wider pools and less deep than in the as-built condition specimens.

HT3 specimens' fractured surfaces are almost completely flat, even at the edges. In addition, the holes are more sparse, as can be seen in the high magnification images in Fig. 13(b,d), which could be caused by the much lower ductility shown by the HT3 specimens.

\section{Microstructure Analysis}

The microstructure of as-built specimens and heat-treated specimens is presented in Fig. 14-Fig. 18. We can see the effect of the specimens' building direction layer by layer in addition to the fusing of each layer along the laser's scan lines on the microstructure of the as-built specimens. In Fig. 14(a) the image shows a stack of layers from the bottom to the top, which indicates the building direction. We can also see the cross-section of the overlapping melt pools, which were scanned in a direction out of the plane. The needle-like microstructure can be observed in the X-built specimens. The needle-like dendritic microstructure seems to be aligned in some preferred orientations. This can be seen easier in Fig. 14(b) at 5kX magnification, where small spherical particles are aligned to create the needle-like patterns in the low magnification micrographs. The microstructure on the tensile force plane for the $Y$-built specimens was very similar to the microstructure shown in Fig. 14(a,b). However, the microstructure on the same plane for the $Z$ building direction is completely different, as can be seen in Fig. 14(c, d). The top of scan lines can be seen since they are aligned in the plane for the Z-built specimens as opposed to the $X$ and $Y$-built specimens, where we can only see the cross-sections of the scan lines and melting pools. No needle-like microstructure can be observed on the Z-built specimens, as shown in Fig. 14(c). Also, the high magnification micrograph of the Z-built specimens Fig. 14(d), shows that the particles are evenly distributed or growing in a direction normal to the imaging plane, thus eliminating the needle-like patterns. Figure 15 highlights the dendritic microstructure and the area it occupies. The X-orientation shows that more dendritic $y$ can be observed than in the Z-orientation, which clarifies differences in texture between the $X$ and Z orientations.

The similarity in the mechanical properties between the $X$ and $Y$-built specimens can be explained by the similarity in the microstructure on the planes normal to the tensile force, as observed in Fig. 14(a). On the other hand, the different microstructure patterns and texture developed in the Z-built specimens as shown in Fig. 14(c) explains the difference in Young's modulus and yield strength displayed by the Z-built specimens compared to the $\mathrm{X}$ and Y-built specimens. Texture is one of the most important factors influencing the lattice strain during loading [56].

HT1 specimens have shown similar microstructure in the low magnification images to the as-built (HT0) specimens. The faint melt pools in the $X$ and $Y$-built specimens can be observed as shown in Fig. 16(a), and the top of the scan lines can be seen in Fig. 16(c). However, needle-like patterns are not present in any of the orientations. The high magnification micrographs show a completely different microstructure than the as-built condition. Plate-like particles, that were not observed in the as-built condition, can be seen from Fig. 16(b, d). The shape and size of these precipitates perfectly match the $\delta$ precipitates of IN718. These precipitates appear to be uniformly distributed with orientations of $\sim \pm 45^{\circ}$ with respect to the building direction. which resulted in the high yield and tensile strengths of the HT1 specimens. The difference in the patterns in the low magnification images explains the different mechanical properties of $\mathrm{X}$ and $\mathrm{Y}$-built specimens compared to the Z-built specimens.

Figure 17 shows the micrographs of HT2 specimens, as can be seen from the low magnification images. In Fig. 17(a, c), the melting pools and laser scan lines are completely replaced by a more homogenous microstructure with more defined grain and grain boundaries. This explains the more isotropic behavior of HT2 specimens. The high 
magnification micrographs Fig. 17(b, d) reveal the absence of precipitates even at the grain boundaries, which explains the lower tensile and yield strength of the HT2 specimens compared to the HT1 specimens.

HT3 micrographs show similar grains to HT2 specimens; however, with more defined grain boundaries due to the large plate-like precipitates present along the grain boundaries, as can be seen in Fig. 18. The high magnification images in panels $b$ and $d$ show a high abundance of these plate-like precipitates along the grain boundaries. The accumulation of $\delta$ precipitates at the grain boundaries of HT3 specimens explains the brittle behavior and the intergranular failure.

\section{XRD Quantitative Analysis}

The Rietveld refinement of the $\gamma, \gamma^{\prime}, \gamma^{\prime \prime}$ and $\delta$ phases was completed successfully. However, the refinement failed to detect the presence of the Laves phase. Figure 19 shows the experimentally observed X-ray spectra, the Rietveld refinement calculated X-ray spectra, and the intensity difference between the observed and calculated spectra for the different heat treatment conditions of the DMLS IN718. The difference plots show that most of the fitting error is caused by the low diffraction angle peaks especially at $2 \theta=51^{\circ}$ which corresponds to the $\{111\}$ of the matrix phase, which could be due to small changes in the lattice of the phases. The results of the quantitative analysis, in addition to the Rietveld profile fitting indices, are summarized in Table 7. The Rietveld refinement has shown that the as-built condition, HTO, has a minimal amount of precipitates, which included $6 \%$ for $\gamma^{\prime \prime}$ and 3.6 for the $\delta$ phase. This explains the low tensile strength of HTO. The standard heat treatment has shown a significant amount of $\gamma^{\prime \prime}$ in addition to $3.6 \%$ of $\gamma^{\prime}$ and the maximum amount of $\delta$ precipitates, which explains the increase in the tensile strength. HT2, on the other hand, showed the maximum volume fraction of $\gamma^{\prime}$ and small amounts of $\gamma^{\prime \prime}$ and $\delta$ precipitates. This increase in $\gamma^{\prime}$ explains the improvement in the tensile strength over the as-built condition and due to small amounts of $\gamma^{\prime \prime}$ and $\delta$ HT2 showed less degradation in its ductility compared to HT1. HT3 showed comparable amounts of precipitates for $Y^{\prime}, Y^{\prime \prime}$, and $\delta$ phases. This makes HT3 the heat treatment with the highest amount of precipitates overall. This confirms the abundance of the plate-like $\delta$ found in the grain boundary of HT3. Therefore, HT3 showed an increase in yield strength over HT2. However, it suffered from low ductility comparable to HT1. This means that the grain boundary $\delta$ precipitates acted as stress concentration regions and led to an intergranular fracture. An additional heat treatment, labelled HT4, was explored where the dwelling time of the first step of the solution annealing heat treatment at $1270^{\circ} \mathrm{C}$ was increased to 10 minutes instead of 5 minutes with the rest of the heat treatment kept exactly as HT3. The result was a further increase in the $\delta$ phase to $18.6 \%$ and a decrease in the $\gamma^{\prime \prime}$ precipitates to $8.6 \%$. The $\gamma^{\prime}$ remained similar to HT3 with $11.2 \%$ instead of $10.3 \%$. The specimens post-processed with this heat treatment performed very poorly and fractured before reaching the yield. The amount of $\delta$ precipitates was confirmed by thresholding the SEM micrographs and calculating the highlighted areas. Figure 20, shows the thresholded micrographs and the calculated areas occupied by the $\delta$ phase. This indicates that the morphology of the $\delta$ precipitates has a significant impact on the mechanical properties. The faction volume of the $\delta$ phase in HT1 is between HT3 and HT4 but the tensile strength and fracture behaviour were significantly different than both, which proves that the different morphology of the $\delta$ phase in $\mathrm{HT} 1$ is the reason and not just the fraction volume. Increasing the homogenization temperature and increased the growth rate of the $\delta$ phase at the grain boundaries. This indicates that depending on the heat treatment, different modes of strengthening will be involved. Furthermore, if the mode of failure is anticipated during the design process, then proper heat treatment can be chosen. 
Table 7

Rietveld refinement results summary

\begin{tabular}{|llllllll|}
\hline Heat treatment & \multicolumn{3}{c}{ Volume fraction [\%] } & \multicolumn{5}{c|}{ Rietveld Refinement agreement } \\
\cline { 2 - 8 } & Y & Y' $^{\prime}$ & $\mathbf{Y}^{\prime \prime}$ & $\delta$ & $\mathbf{R}_{\text {expected }}$ & $\mathbf{R}_{\text {weighted }}$ & Goodness of fit \\
\hline HT0 & 90.4 & 0.0 & 6.0 & 3.6 & 3.106 & 6.606 & 4.523 \\
\hline HT1 & 71.7 & 4.4 & 9.1 & 14.8 & 3.118 & 4.777 & 2.348 \\
\hline HT2 & 75.9 & 16.7 & 4.6 & 2.8 & 3.086 & 5.885 & 3.636 \\
HT3 & 65.9 & 10.3 & 12.9 & 11.0 & 2.972 & 6.989 & 5.529 \\
\hline
\end{tabular}

\section{Conclusion}

In this study, two solution annealing heat treatments were proposed and investigated to understand their influence on the phase composition of precipitates, microstructure, and tensile mechanical properties of the additively manufactured IN718. The as-built condition and standard heat treatment were also investigated for comparison. To study the effect of the heat treatments on the anisotropy, samples were fabricated in three different orientations, namely $X, Y, Z$, for each heat treatment. To account for repeatability, three identical specimens were tested for each heat treatment and building direction. This work demonstrated that:

- The mechanical properties such as tensile strength, yield strength, and Young's modulus of as-built DMLS IN718 and standard heat treatment condition depend on the orientation of the specimens, which demonstrates high anisotropy. The microstructure exposed on the surfaces normal to the tensile stress showed different patterns depending on the orientation of the specimen. The similarity in the microstructure in the as-built condition and the standard heat treatment demonstrates the failure of the standard heat treatment to homogenize the microstructure and reduce the anisotropy in the mechanical properties.

- The proposed modifications to the solution annealing heat treatments by including an initial step at 1200 or $1270^{\circ} \mathrm{C}$ for less than 20 minutes and shorting the duration of the $980^{\circ} \mathrm{C}$ step to $20-40$ minutes instead of one hour resulted in homogenizing the microstructure and making it similar to heat-treated wrought or cast IN718. This reduced the anisotropy and improved the repeatability of the mechanical properties regardless of the specimen's orientation.

- The XRD analysis and Rietveld refinement have proved that changing the solution annealing heat treatment by including an additional step prior to the $980^{\circ} \mathrm{C}$ has a significant impact on the phases that can precipitate during aging. In the standard heat treatment $\gamma^{\prime \prime}$ is usually 3-4 times the volume fraction of $\gamma^{\prime}$ but for additively manufactured IN718 the volume fraction of $\gamma^{\prime \prime}$ was larger than $\gamma^{\prime}$ by a factor of 2 , in addition to $~ 15 \% \delta$. By adding the $1200^{\circ} \mathrm{C}$ step the volume fraction $\gamma^{\prime}$ is four times the volume fraction of $\gamma^{\prime \prime}$ precipitates. This change in the volume fraction of the strengthening phases has shown a good combination of high strength and ductility in comparison to the standard heat treatment which has higher strength but lower ductility. This can be correlated to the volume fraction of the strengthening precipitates, in which $\gamma^{\prime \prime}$ provides superior strength in comparison to $\gamma^{\prime}$ but reduces the ductility. Replacing the $1200^{\circ} \mathrm{C}$ step with $1270^{\circ} \mathrm{C}$ resulted in a significant increase in the $\delta$ phase precipitates in the grain boundaries which resulted in reducing the ductility without significant improvement to the strength.

- This work demonstrates that adding prior heating steps at $1200^{\circ} \mathrm{C}$ or $1270^{\circ} \mathrm{C}$ and limiting the dwelling time to 520 minutes has proved effective in limiting the grain growth of the microstructure, while effectively homogenizing the microstructure. In comparison, work in the literature has shown significant grain growth when homogenization 
is done by increasing the dwelling time to 3 hours or by including a hot isostatic pressing treatment. Furthermore, reducing the duration of the initial step and the $980^{\circ} \mathrm{C}$ step to $20-40$ minutes reduces the energy cost and the total post-processing time.

- Homogenizing the microstructure at $1200^{\circ} \mathrm{C}$ prior to solution annealing (HT2) is a suitable heat treatment program for parts in low-cycle fatigue application, which requires good ductility and HT2 provides a good combination of strength and ductility. HT1 provides the maximum tensile strength which makes it a suitable candidate for highcycle fatigue applications.

\section{Declarations Funding}

This research did not receive any specific grant from funding agencies in the public, commercial, or not-for-profit sectors.

\section{Conflicts of interest}

On behalf of all authors, the corresponding author states that there is no conflict of interest.

\section{Data Availability}

The datasets generated during and/or analysed during the current study are available in the Zenodo repository, DOI: $10.5281 /$ zenodo.5091288 (This is the reserved DOI. Currently, the data can be viewed here https://github.com/aalafaghani/Modified-HT-IN718-data).

\section{References}

1. Mortezaie, A., \& Shamanian, M. (2014). An assessment of microstructure, mechanical properties and corrosion resistance of dissimilar welds between Inconel 718 and 310S austenitic stainless steel. Int. J. Press. Vessel. Pip, 116, 37-46. https://doi.org/10.1016/j.ijpvp.2014.01.002.

2. Kwon, S. I. L., Bae, S. H., Do, J. H., Jo, C. Y., \& Hong, H. U. (2016). Characterization of the Microstructures and the Cryogenic Mechanical Properties of Electron Beam Welded Inconel 718, Metall. Mater. Trans. A, 47, 777-787. https://doi.org/10.1007/s11661-015-3269-6.

3. Alafaghani, A., Qattawi, A., \& Castañón, M. A. G. (2018). Effect of manufacturing parameters on the microstructure and mechanical properties of metal laser sintering parts of precipitate hardenable metals. Int. J. Adv. Manuf. Technol, 99, 2491-2507. https://doi.org/10.1007/s00170-018-2586-5.

4. Metals, S., \& INCONEL ALLOY 718. (2007)., 1-28.

http://www.specialmetals.com/assets/smc/documents/inconel_alloy_718.pdf (accessed January 3, 2018).

5. Patel, S. J. (2006). A century of discoveries, inventors, and new nickel alloys. JOM, 58, 18-20. https://doi.org/10.1007/s11837-006-0076-y.

6. Pinheiro, C., Kondo, M. Y., Amaral, S. S., Callisaya, E. S., De Souza, J. V. C., De Sampaio Alves, M. C., \& Ribeiro, M. V. (2021). Effect of machining parameters on turning process of Inconel 718. Mater. Manuf. Process. https://doi.org/10.1080/10426914.2021.1914839.

Page 14/34 
7. Mahesh, K., Philip, J. T., Joshi, S. N., \& Kuriachen, B. (2021). Machinability of Inconel 718: A critical review on the impact of cutting temperatures. Mater. Manuf. Process, 36, 753-791.

https://doi.org/10.1080/10426914.2020.1843671.

8. Sonia, P., Jain, J. K., \& Saxena, K. K. (2021). Influence of ultrasonic vibration assistance in manufacturing processes: A Review. Mater. Manuf. Process. https://doi.org/10.1080/10426914.2021.1914843.

9. Casalino, G., Campanelli, S. L., Contuzzi, N., \& Ludovico, A. D. (2015). Experimental investigation and statistical optimisation of the selective laser melting process of a maraging steel. Opt. Laser Technol, 65, 151-158. https://doi.org/10.1016/j.optlastec.2014.07.021.

10. Schneider, J., Lund, B., \& Fullen, M. (2018). Effect of heat treatment variations on the mechanical properties of Inconel 718 selective laser melted specimens. Addit. Manuf, 21, 248-254. https://doi.org/10.1016/j.addma.2018.03.005.

11. Bean, G. E., McLouth, T. D., Witkin, D. B., Sitzman, S. D., Adams, P. M., \& Zaldivar, R. J. (2019). Build Orientation Effects on Texture and Mechanical Properties of Selective Laser Melting Inconel 718. J. Mater. Eng. Perform, 28, 1942-1949. https://doi.org/10.1007/s11665-019-03980-w.

12. Polonsky, A. T., Echlin, M. P., Lenthe, W. C., Dehoff, R. R., Kirka, M. M., \& Pollock, T. M. (2018). Defects and 3D structural inhomogeneity in electron beam additively manufactured Inconel 718. Mater. Charact, 143, 171-181. https://doi.org/10.1016/j.matchar.2018.02.020.

13. Zhang, Z., Yao, X. X., \& Ge, P. (2020). Phase-field-model-based analysis of the effects of powder particle on porosities and densities in selective laser sintering additive manufacturing. Int. J. Mech. Sci, 166, 105230. https://doi.org/10.1016/J.IJMECSCI.2019.105230.

14. Xia, M., Gu, D., Yu, G., Dai, D., Chen, H., \& Shi, Q. (2016). Influence of hatch spacing on heat and mass transfer, thermodynamics and laser processability during additive manufacturing of Inconel 718 alloy. Int. J. Mach. Tools Manuf, 109, 147-157. https://doi.org/10.1016/j.ijmachtools.2016.07.010.

15. Walker, T. R., Bennett, C. J., Lee, T. L., \& Clare, A. T. (2019). A validated analytical-numerical modelling strategy to predict residual stresses in single-track laser deposited IN718. Int. J. Mech. Sci, 151, 609-621.

https://doi.org/10.1016/J.IJMECSCI.2018.12.004.

16. Ghasri-Khouzani, M., Peng, H., Rogge, R., Attardo, R., Ostiguy, P., Neidig, J. ... Shankar, M. R. (2017). Experimental measurement of residual stress and distortion in additively manufactured stainless steel components with various dimensions. Mater. Sci. Eng. A, 707, 689-700. https://doi.org/10.1016/j.msea.2017.09.108.

17. Afkhami, S., Dabiri, M., Alavi, S. H., Björk, T., \& Salminen, A. (2019). Fatigue characteristics of steels manufactured by selective laser melting. Int. J. Fatigue, 122, 72-83. https://doi.org/10.1016/j.ijfatigue.2018.12.029.

18. Zhang, B., Li, Y., \& Bai, Q. (2017). Defect Formation Mechanisms in Selective Laser Melting: A Review. Chinese J. Mech. Eng, 30, 515-527. https://doi.org/10.1007/s10033-017-0121-5.

19. Beretta, S., \& Romano, S. (2017). A comparison of fatigue strength sensitivity to defects for materials manufactured by AM or traditional processes. Int. J. Fatigue, 94, 178-191.

https://doi.org/10.1016/j.ijfatigue.2016.06.020.

20. Aboutaleb, A. M., Mahtabi, M. J., Tschopp, M. A., \& Bian, L. (2019). Multi-objective accelerated process optimization of mechanical properties in laser-based additive manufacturing: Case study on Selective Laser Melting (SLM) Ti-6Al-4V. J. Manuf. Process, 38, 432-444. https://doi.org/10.1016/j.jmapro.2018.12.040.

21. Singh, N., Ummethala, R., Hameed, P., Sokkalingam, R., \& Prashanth, K. G. (2020). Competition between densification and microstructure of functionalmaterials by Selective Laser Melting. Mater. Des. Process. Commun. https://doi.org/10.1002/mdp2.146.mdp2.146

Page $15 / 34$ 
22. Cacace, S., Demir, A. G., \& Semeraro, Q. (2017). Densification Mechanism for Different Types of Stainless Steel Powders in Selective Laser Melting, Procedia CIRP. 62475-480. https://doi.org/10.1016/j.procir.2016.06.010.

23. Yan, M., \& Yu, P. An Overview of Densification, Microstructure and Mechanical Property of Additively Manufactured Ti-6Al-4V - Comparison among Selective Laser Melting, Electron Beam Melting, Laser Metal Deposition and Selective Laser Sintering, and with Conventional Powder, in: Sinter. Tech. Mater., InTech(2015). https://doi.org/10.5772/59275.

24. Choi, J. P., Shin, G. H., Brochu, M., Kim, Y. J., Yang, S. S., Kim, K. T. ... Yu, J. H., Densification Behavior of 316L Stainless Steel Parts Fabricated by Selective Laser Melting by Variation in Laser Energy Density,Mater. Trans.57 (2016)1952-1959. https://doi.org/10.2320/matertrans.M2016284.

25. Mezzetta, J., Choi, J. P., Milligan, J., Danovitch, J., Chekir, N., Bois-Brochu, A. ... Brochu, M. (2018). MicrostructureProperties Relationships of Ti-6Al-4V Parts Fabricated by Selective Laser Melting. Int. J. Precis. Eng. Manuf. Technol. 2018, 55(5), 605-612. https://doi.org/10.1007/S40684-018-0062-1.

26. Yeo, I., Bae, S., Amanov, A., \& Jeong, S. (2020). Effect of Laser Shock Peening on Properties of Heat-Treated Ti6Al-4V Manufactured by Laser Powder Bed Fusion. Int. J. Precis. Eng. Manuf. Technol, 2020 84, 1137-1150. https://doi.org/10.1007/S40684-020-00234-2.

27. Mignanelli, P. M., Jones, N. G., Pickering, E. J., Messé, O. M. D. M., Rae, C. M. F., Hardy, M. C., \& Stone, H. J. (2017). Gamma-gamma prime-gamma double prime dual-superlattice superalloys. Scr. Mater, 136, 136-140. https://doi.org/10.1016/j.scriptamat.2017.04.029.

28. Tabaie, S., Rézaï-Aria, F., Flipo, B. C. D., Cormier, J., \& Jahazi, M. (2021). Metall. Mater. Trans. A Phys. Metall. Mater. Sci, 52, 3475-3488. https://doi.org/10.1007/s11661-021-06319-0.Post-Weld Heat Treatment of Additively Manufactured Inconel 718 Welded to Forged Ni-Based Superalloy AD730 by Linear Friction Welding

29. Deng, D., Moverare, J., Peng, R. L., \& Söderberg, H. (2017). Microstructure and anisotropic mechanical properties of EBM manufactured Inconel 718 and effects of post heat treatments. Mater. Sci. Eng. A, 693, 151-163. https://doi.org/10.1016/j.msea.2017.03.085.

30. Deng, D., Peng, R. L., Brodin, H., \& Moverare, J. (2018). Microstructure and mechanical properties of Inconel 718 produced by selective laser melting: Sample orientation dependence and effects of post heat treatments. Mater. Sci. Eng. A, 713, 294-306. https://doi.org/10.1016/j.msea.2017.12.043.

31. Zhang, D., Niu, W., Cao, X., \& Liu, Z. (2015). Effect of standard heat treatment on the microstructure and mechanical properties of selective laser melting manufactured Inconel 718 superalloy. Mater. Sci. Eng. A, 644, 3240. https://doi.org/10.1016/j.msea.2015.06.021.

32. Konečná, R., Nicoletto, G., Kunz, L., \& Bača, A. (2016). Microstructure and directional fatigue behavior of Inconel 718 produced by selective laser melting. Procedia Struct. Integr, 2, 2381-2388. https://doi.org/10.1016/j.prostr.2016.06.298.

33. Johnson, A. S., Shao, S., Shamsaei, N., Thompson, S. M., \& Bian, L. (2017). Microstructure, Fatigue Behavior, and Failure Mechanisms of Direct Laser-Deposited Inconel 718, JOM. 69597-603. https://doi.org/10.1007/s11837016-2225-2.

34. Sprengel, M., Baca, A., Gumpinger, J., Connolley, T., Brandao, A., Rohr, T., \& Ghidini, T. (2019). Fatigue Properties of Powder Bed Fused Inconel 718 in As-Built Surface Condition (pp. 91-97). Cham: in: Springer. https://doi.org/10.1007/978-3-030-13980-3_12.

35. Raghavan, S., Zhang, B., Wang, P., Sun, C. N., Nai, M. L. S., Li, T., \& Wei, J. (2017). Effect of different heat treatments on the microstructure and mechanical properties in selective laser melted INCONEL 718 alloy. Mater. Manuf. Process, 32, 1588-1595. https://doi.org/10.1080/10426914.2016.1257805. 
36. Aydinöz, M. E., Brenne, F., Schaper, M., Schaak, C., Tillmann, W., Nellesen, J., \& Niendorf, T. (2016). On the microstructural and mechanical properties of post-treated additively manufactured Inconel 718 superalloy under quasi-static and cyclic loading. Mater. Sci. Eng. A, 669, 246-258. https://doi.org/10.1016/j.msea.2016.05.089.

37. Li, X., Shi, J. J., Cao, G. H., Russell, A. M., Zhou, Z. J., Li, C. P., \& Chen, G. F. (2019). Improved plasticity of Inconel 718 superalloy fabricated by selective laser melting through a novel heat treatment process. Mater. Des, 180, 107915. https://doi.org/10.1016/j.matdes.2019.107915.

38. Sangid, M. D., Book, T. A., Naragani, D., Rotella, J., Ravi, P., Finch, A. ... Xiao, X. (2018). Role of heat treatment and build orientation in the microstructure sensitive deformation characteristics of IN718 produced via SLM additive manufacturing. Addit. Manuf, 22, 479-496. https://doi.org/10.1016/j.addma.2018.04.032.

39. Huang, L., Cao, Y., Zhang, J., Gao, X., Li, G., \& Wang, Y. (2021). Effect of heat treatment on the microstructure evolution and mechanical behaviour of a selective laser melted Inconel 718 alloy. J. Alloys Compd, 865, 158613. https://doi.org/10.1016/j.jallcom.2021.158613.

40. Wang, Y., \& Shi, J. (2020). Effect of post heat treatment on the microstructure and tensile properties of nano TiC particulate reinforced inconel 718 by selective laser melting. J. Manuf. Sci. Eng. Trans. ASME, 142. https://doi.org/10.1115/1.4046646.

41. Zhao, Y., Guan, K., Yang, Z., Hu, Z., Qian, Z., Wang, H., \& Ma, Z. (2020). The effect of subsequent heat treatment on the evolution behavior of second phase particles and mechanical properties of the Inconel 718 superalloy manufactured by selective laser melting. Mater. Sci. Eng. A, 794, 139931. https://doi.org/10.1016/j.msea.2020.139931.

42. Wang, W., Wang, S., Zhang, X., Chen, F., Xu, Y., \& Tian, Y. (2021). Process parameter optimization for selective laser melting of Inconel 718 superalloy and the effects of subsequent heat treatment on the microstructural evolution and mechanical properties. J. Manuf. Process, 64, 530-543. https://doi.org/10.1016/j.jmapro.2021.02.004.

43. Tucho, W. M., \& Hansen, V. (2019). Characterization of SLM-fabricated Inconel 718 after solid solution and precipitation hardening heat treatments. J. Mater. Sci, 54, 823-839. https://doi.org/10.1007/s10853-018-2851-x.

44. Xie, B., Li, L., Fang, Q., Li, J., Liu, B., Huang, Z., \& Tan, L. (2021). Evolution of residual stress and its impact on Nibased superalloy. Int. J. Mech. Sci, 202-203. 106494. https://doi.org/10.1016/J.IJMECSCI.2021.106494.

45. Tillmann, W., Schaak, C., Nellesen, J., Schaper, M., Aydinöz, M. E., \& Hoyer, K. P. (2017). Hot isostatic pressing of IN718 components manufactured by selective laser melting. Addit. Manuf, 13, 93-102. https://doi.org/10.1016/j.addma.2016.11.006.

46. Seifi, M., Salem, A. A., Satko, D. P., Grylls, R., \& Lewandowski, J. J. (2018). Effects of Post-processing on Microstructure and Mechanical Properties of SLM-Processed IN-718. Miner. Met. Mater. Ser., Springer International Publishing, 515-526. https://doi.org/10.1007/978-3-319-89480-5_33.

47. Goel, S., Ahlfors, M., Bahbou, F., \& Joshi, S. (2019). Effect of Different Post-treatments on the Microstructure of EBM-Built Alloy 718. J. Mater. Eng. Perform, 28, 673-680. https://doi.org/10.1007/s11665-018-3712-0.

48. International, A. Standard Specification for Additive Manufacturing Nickel Alloy (UNS N07718) with Powder Bed Fusion F3055, ASTM Stand(2014). 1-8. https://www.astm.org/Standards/F3055.htm (accessed March 12, 2021).

49. Schneider, J. (2020). Comparison of Microstructural Response to Heat Treatment of Inconel 718 Prepared by Three Different Metal Additive Manufacturing Processes. JOM, 72, 1085-1091. https://doi.org/10.1007/s11837-02004021-x.

50. Sames, W. J., Unocic, K. A., Helmreich, G. W., Kirka, M. M., Medina, F., Dehoff, R. R., \& Babu, S. S. (2017). Feasibility of in situ controlled heat treatment (ISHT) of Inconel 718 during electron beam melting additive manufacturing. Addit. Manuf, 13, 156-165. https://doi.org/10.1016/j.addma.2016.09.001. 
51. Alafaghani, A., Qattawi, A., \& Ablat, M. A. (2017). Design Consideration for Additive Manufacturing: Fused Deposition Modelling. Open J. Appl. Sci, 07, 291-318. https://doi.org/10.4236/ojapps.2017.76024.

52. ASTM, F. (2012). 2921 - Standard Terminology for Additive Manufacturing - Coordinate Systems and Test. Am. Soc. Test. Mater. i, 12. https://doi.org/10.1520/F2921.

53. ASTM Int. (2009). ASTM, Standard Test Methods for Tension Testing of Metallic Materials. Astm, 1-27. https://doi.org/10.1520/E0008.

54. Silva, C., Song, M., Leonard, K., Wang, M., Was, G., \& Busby, J. (2017). Characterization of alloy 718 subjected to different thermomechanical treatments. Mater. Sci. Eng. A, 691, 195-202.

https://doi.org/10.1016/j.msea.2017.03.045.

55. Slama, C., \& Abdellaoui, M. (2000). Structural characterization of the aged Inconel 718. J. Alloys Compd, 306, 277-284. https://doi.org/10.1016/S0925-8388(00)00789-1.

56. Schröder, J., Mishurova, T., Fritsch, T., Serrano-Munoz, I., Evans, A., Sprengel, M. ... Bruno, G. (2021). On the influence of heat treatment on microstructure and mechanical behavior of laser powder bed fused Inconel 718. Mater. Sci. Eng. A, 805, 140555. https://doi.org/10.1016/j.msea.2020.140555.

\section{Figures}

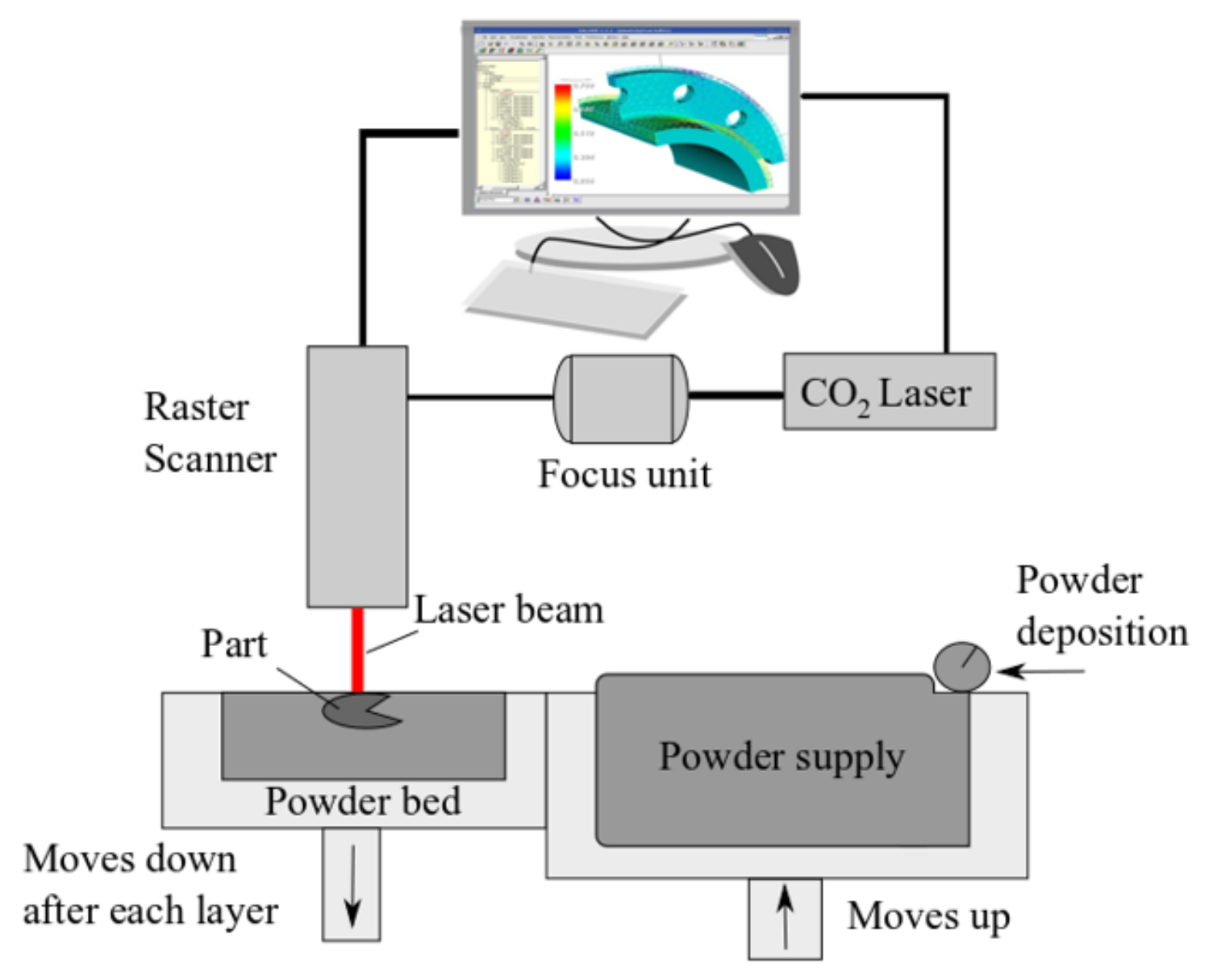

Figure 1

Schematic of PBF process 


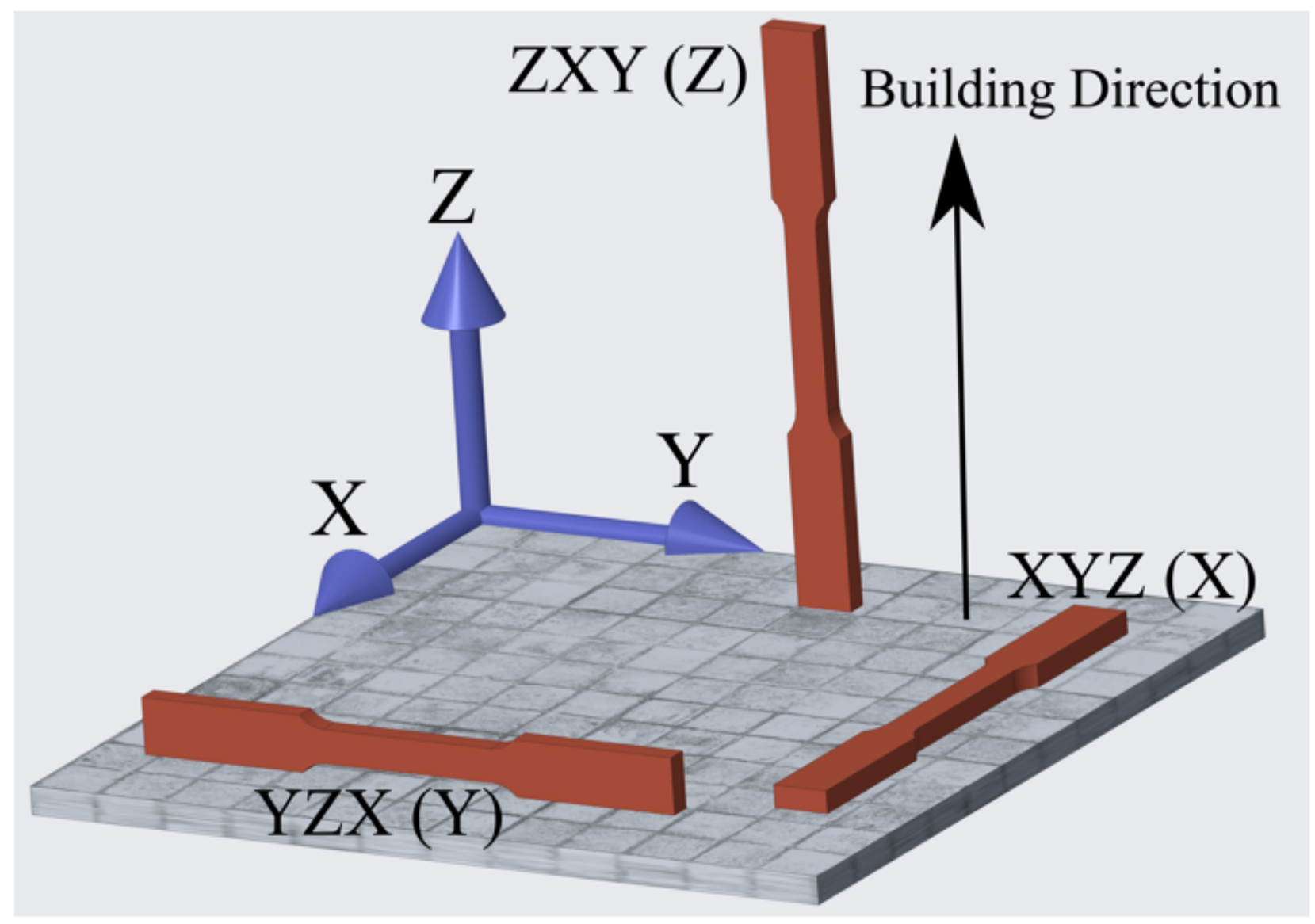

Figure 2

The three orientations used in fabricating the specimens 


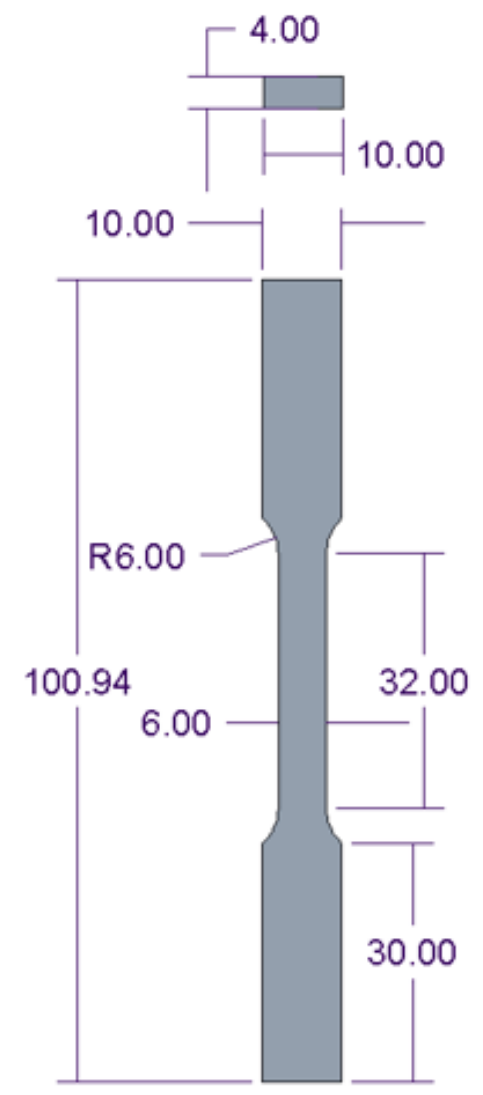

Figure 3

The geometry of the tensile specimens. Dimensions are in millimetre.
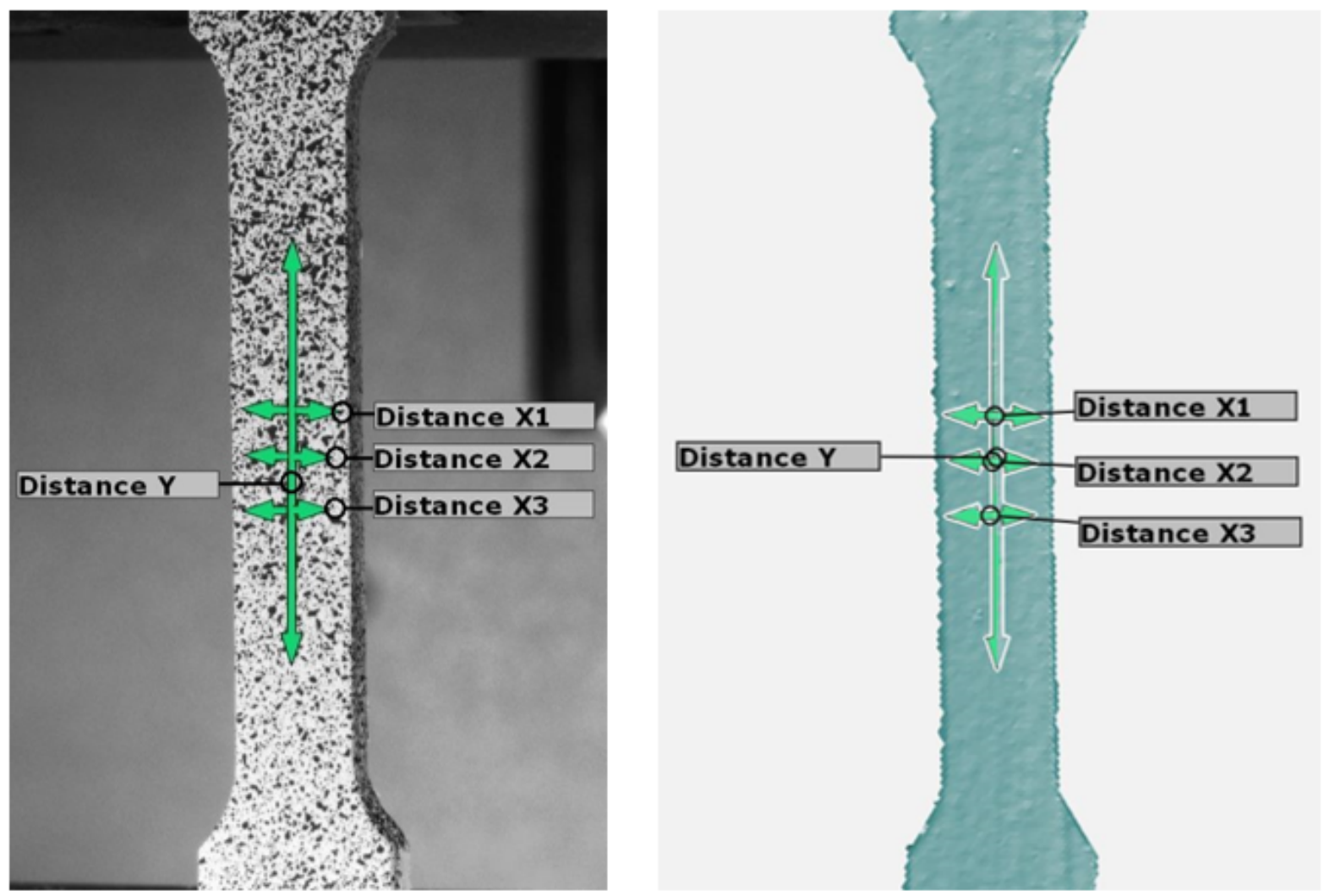
Figure 4

The generated 3D surface using DIC for the tensile specimens. The left image showing the surface imposed on the image of the specimen, while the right image showing the surface by itself
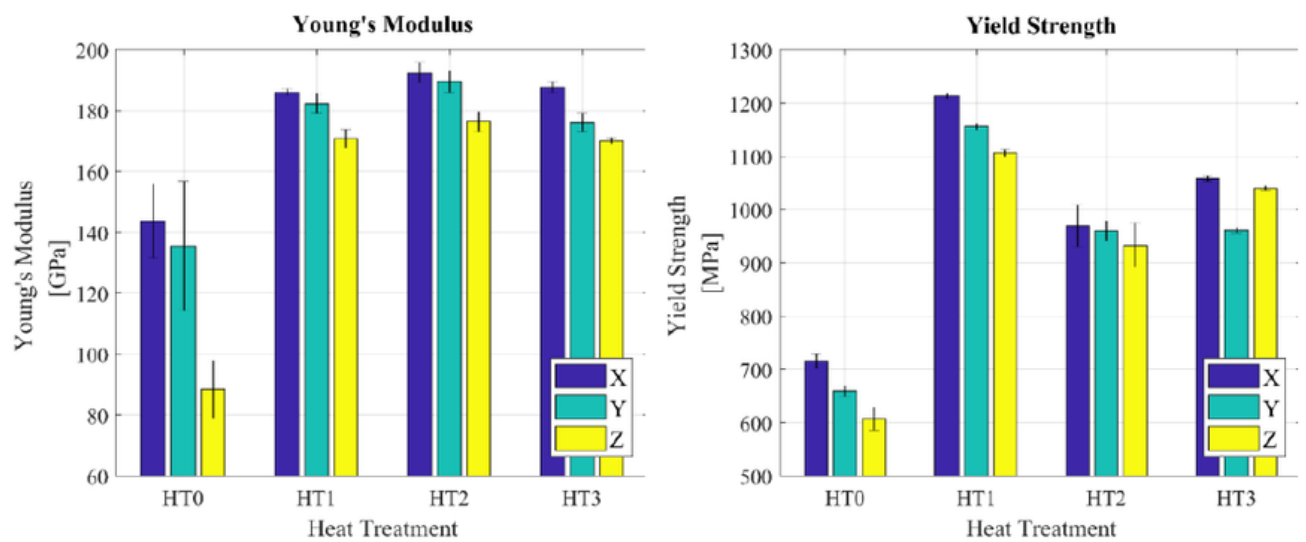

a

b
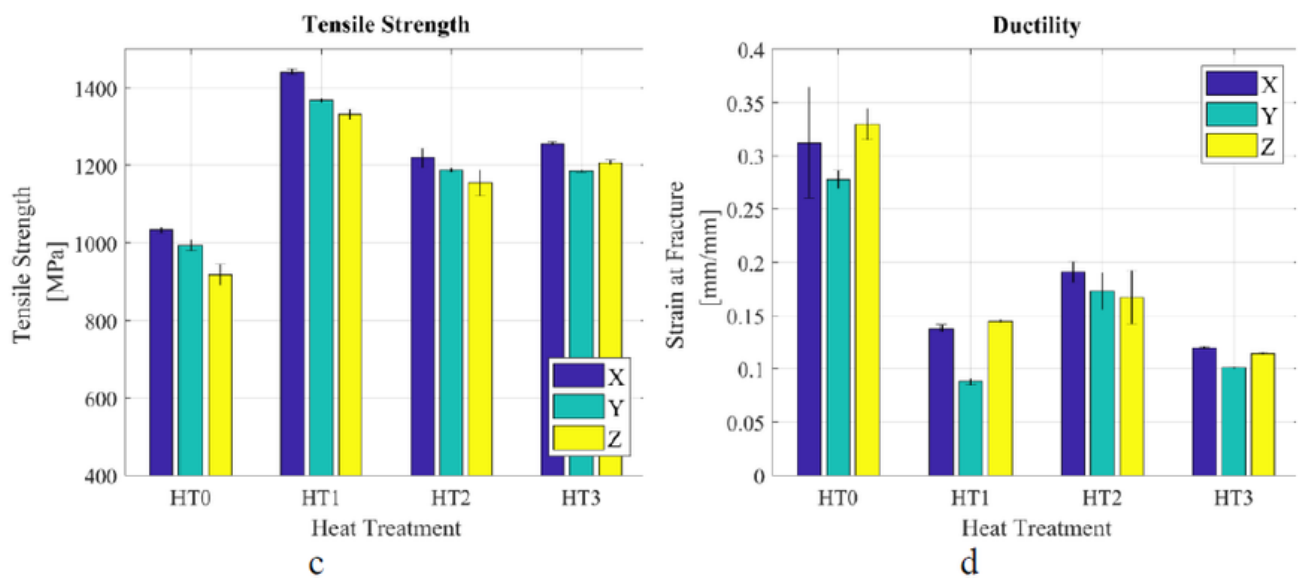

Poisson's Ratio

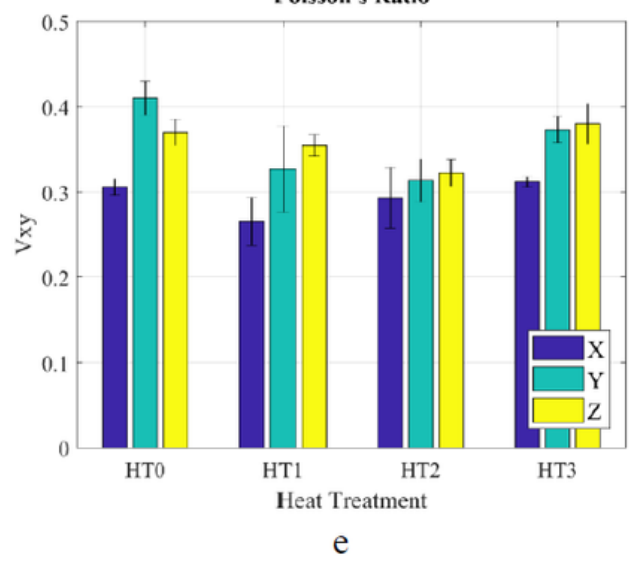

Figure 5

Tensile test mechanical properties of DMLS IN718 fabricated in different orientations X,Y, and Z and post processed with different solution annealing heat treatments HT1, HT2, HT3 in addition to the as-built condition HTO. a) Young's modulus, b) Yield strength, c) Tensile strength, d) Ductility, e) Poisson's ratio 


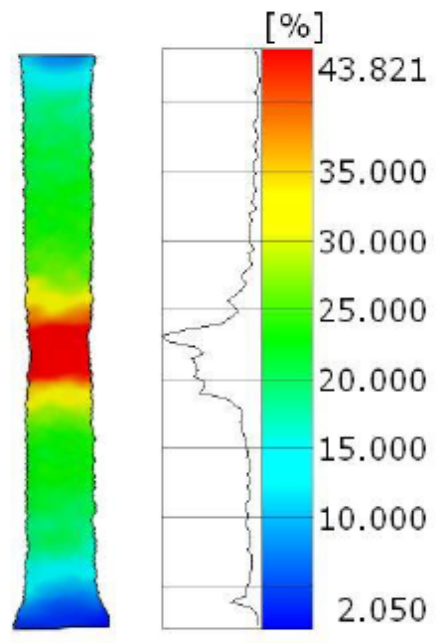

a
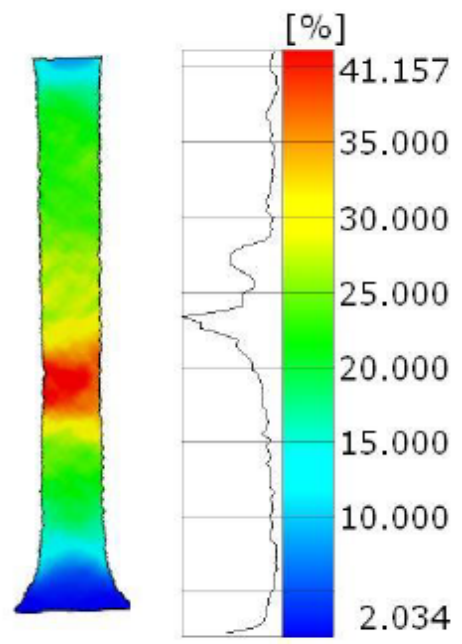

$\mathrm{b}$
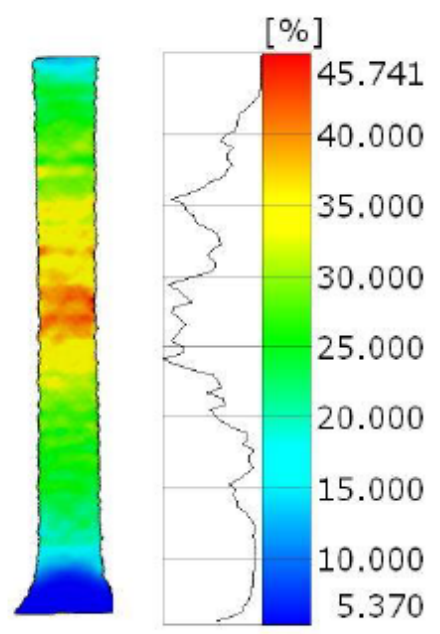

$\mathrm{C}$

\section{Figure 6}

Strain fields of as-built (HT0) DMLS IN718 specimens generated by the DIC system. a) X-built specimen just before fracture. b) Y-built specimen just before fracture. c) Z-built specimen just before fracture

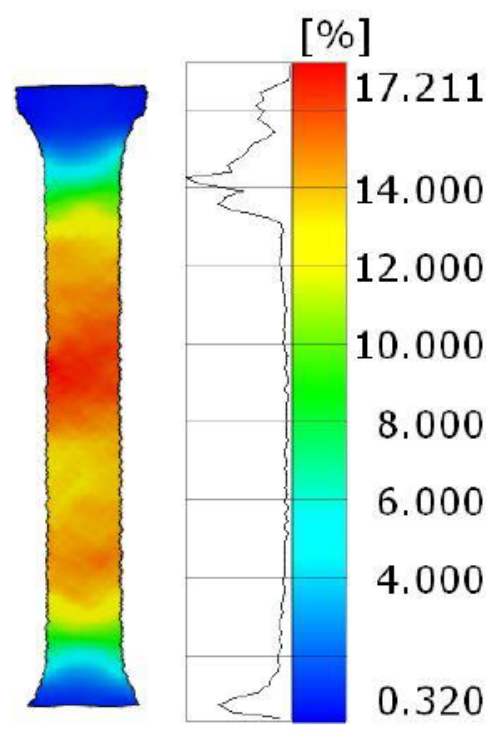

a

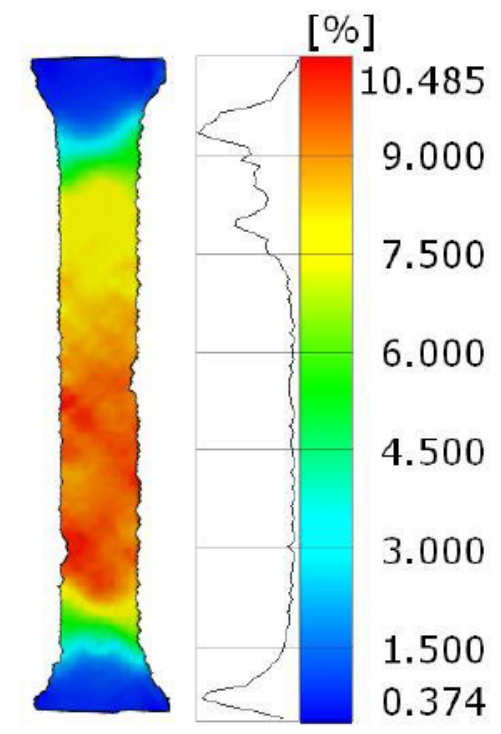

b

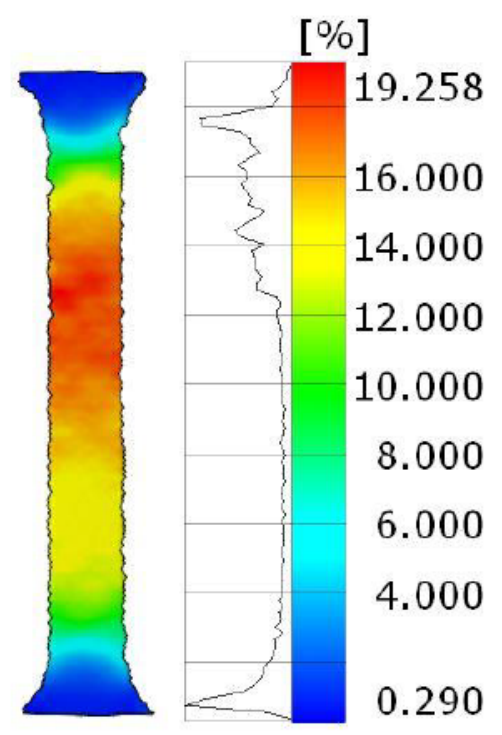

$\mathrm{c}$

\section{Figure 7}

Strain fields of HT1 DMLS IN718 specimens generated by the DIC system. a) X-built specimen just before fracture. b) Y-built specimen just before fracture. c) Z-built specimen just before fracture 


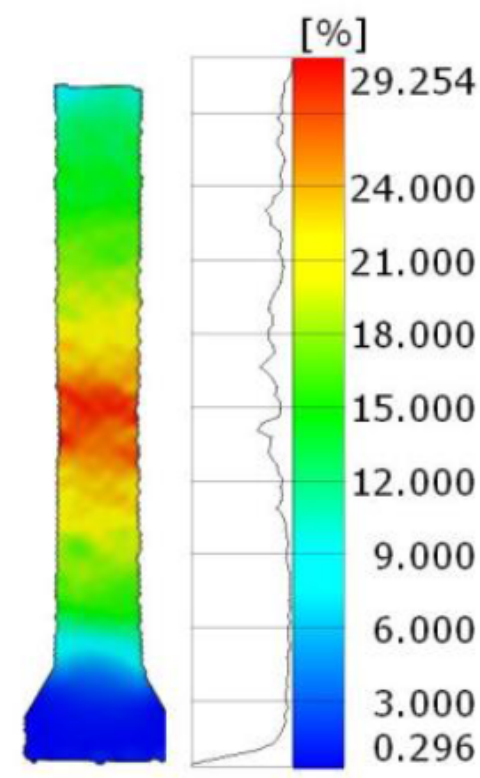

a

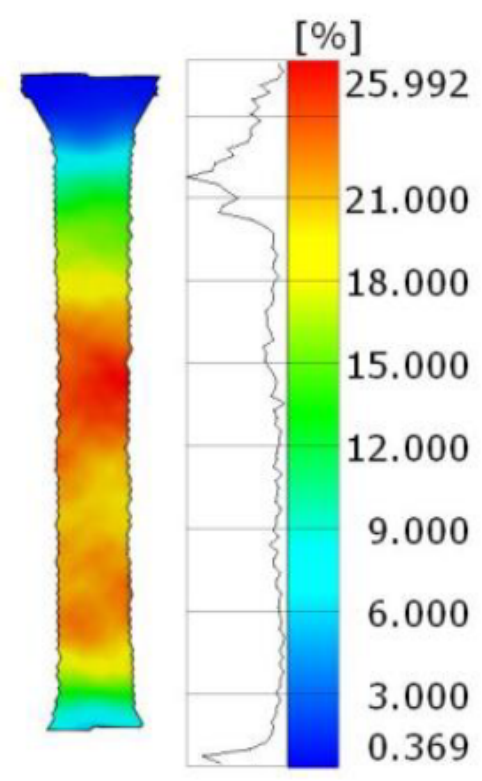

b

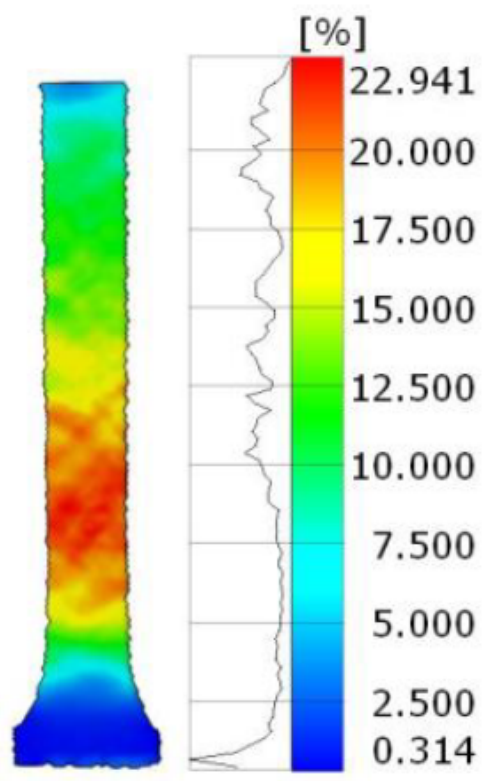

c

Figure 8

Strain fields of HT2 DMLS IN718 specimens generated by the DIC system. a) X-built specimen just before fracture. b) Y-built specimen just before fracture. c) Z-built specimen just before fracture

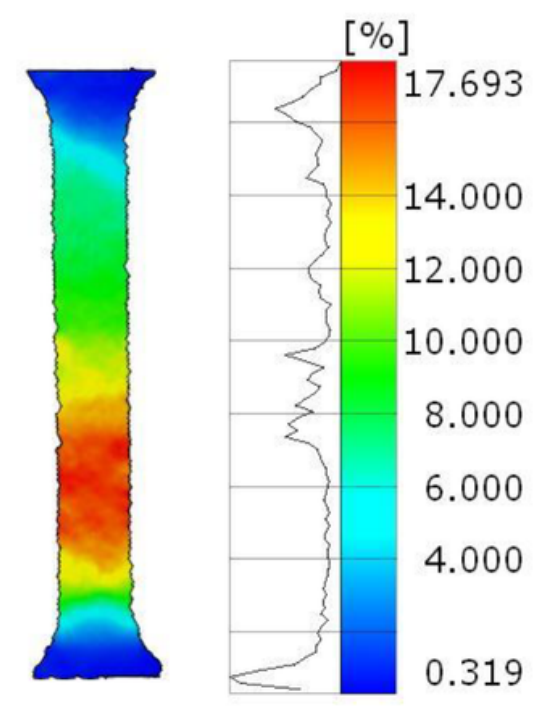

a
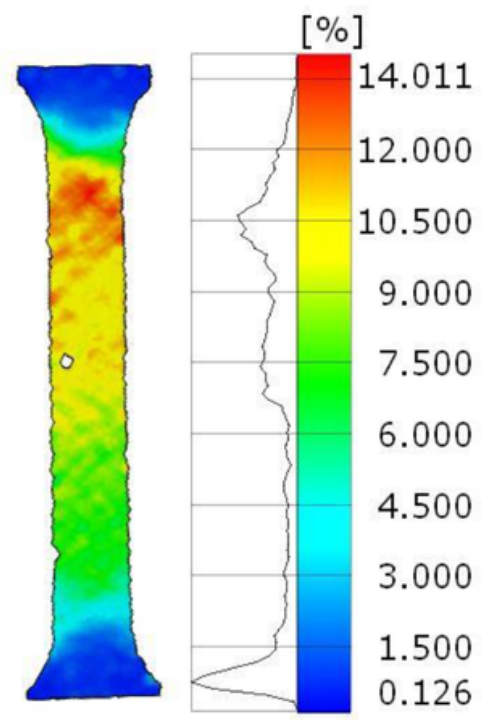

b

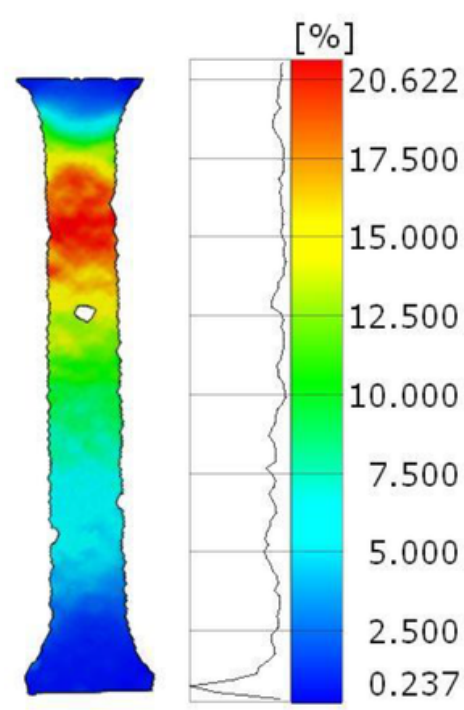

c

Figure 9

Strain fields of HT3 DMLS IN718 specimens generated by the DIC system. a) X-built specimen just before fracture. b) Y-built specimen just before fracture. c) Z-built specimen just before fracture 

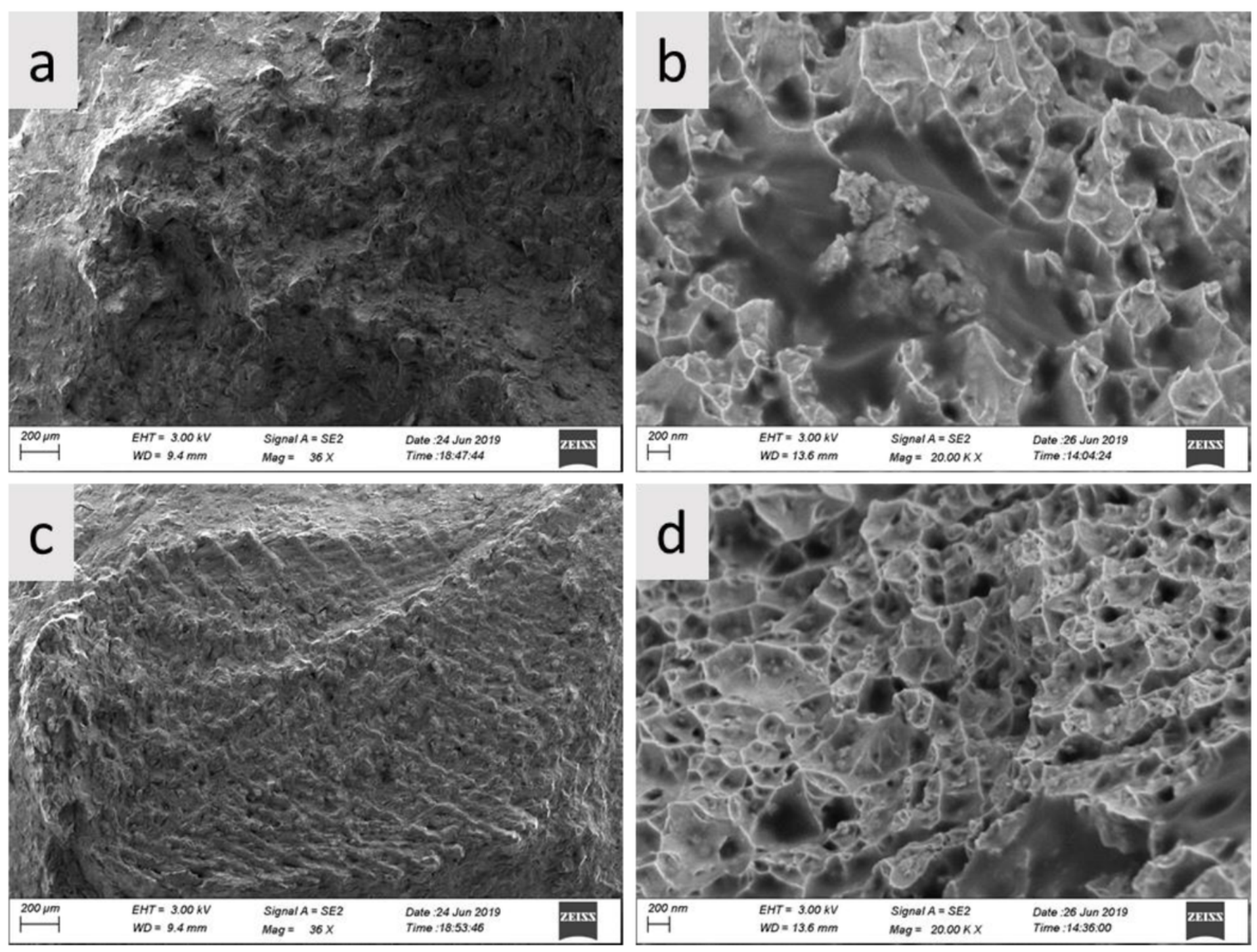

\section{Figure 10}

SEM fractography of as-built IN718 (HT0). a) X-building direction at 36X magnification. b) X-building direction at 20KX magnification. c) Z-building direction at 36X magnification. d) Z-building direction at 20KX magnification 

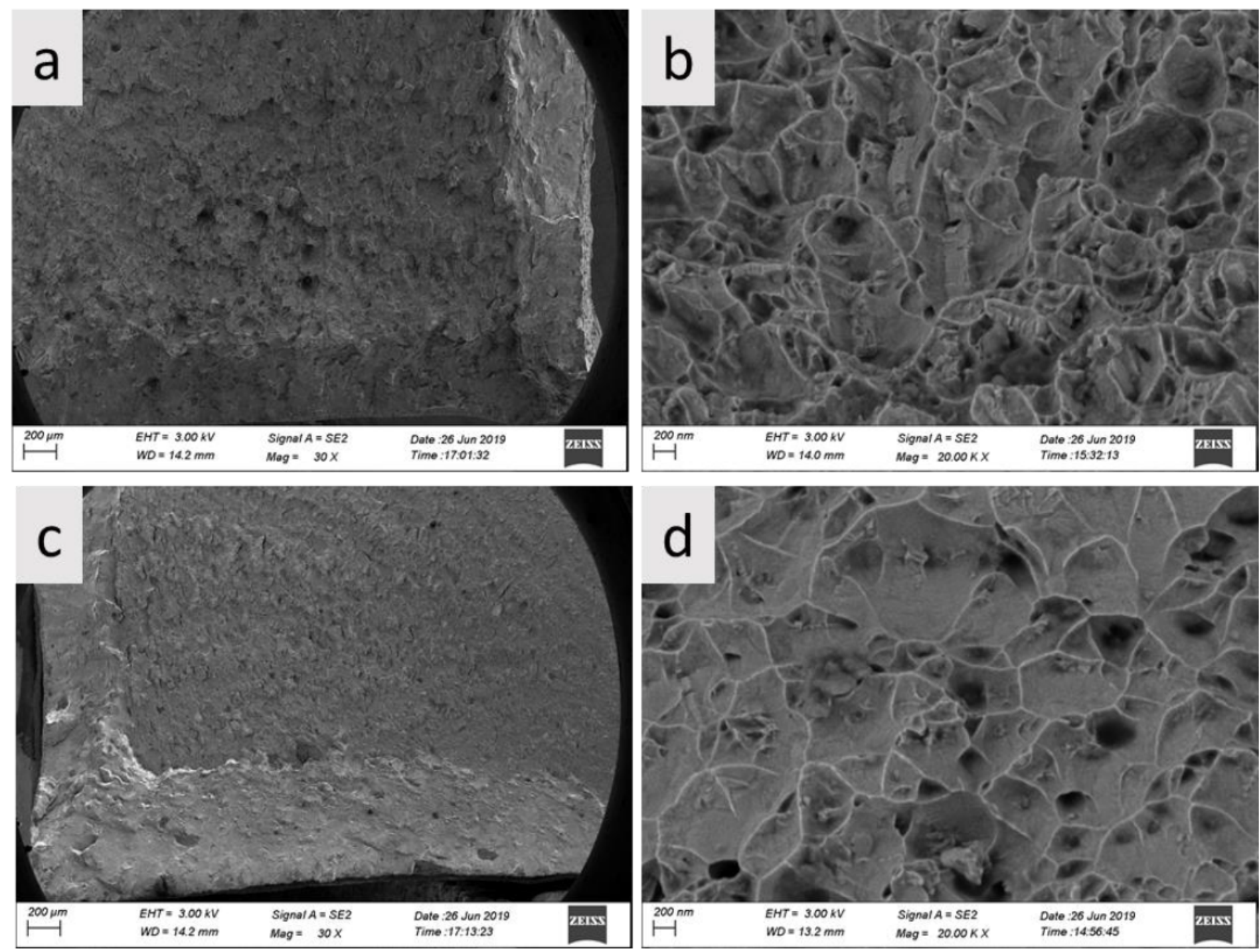

Figure 11

SEM fractography of HT1 IN718. a) X-building direction at 30X magnification. b) X-building direction at 20KX magnification. c) Z-building direction at 30X magnification. d) Z-building direction at 20KX magnification 

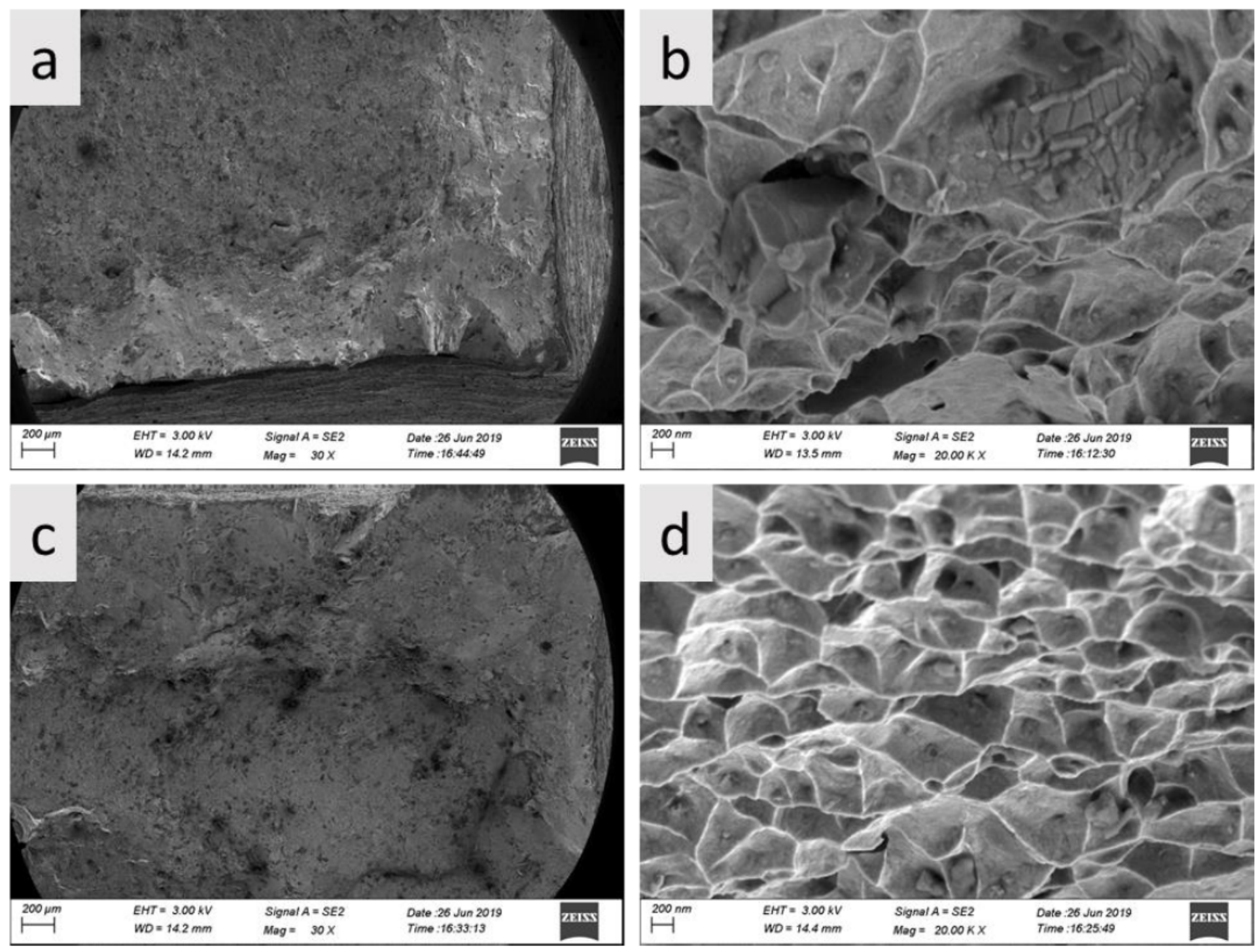

\section{Figure 12}

SEM fractography of HT2 IN718. a) X-building direction at 30X magnification. b) X-building direction at 20KX magnification. c) Z-building direction at 30X magnification. d) Z-building direction at 20KX magnification 

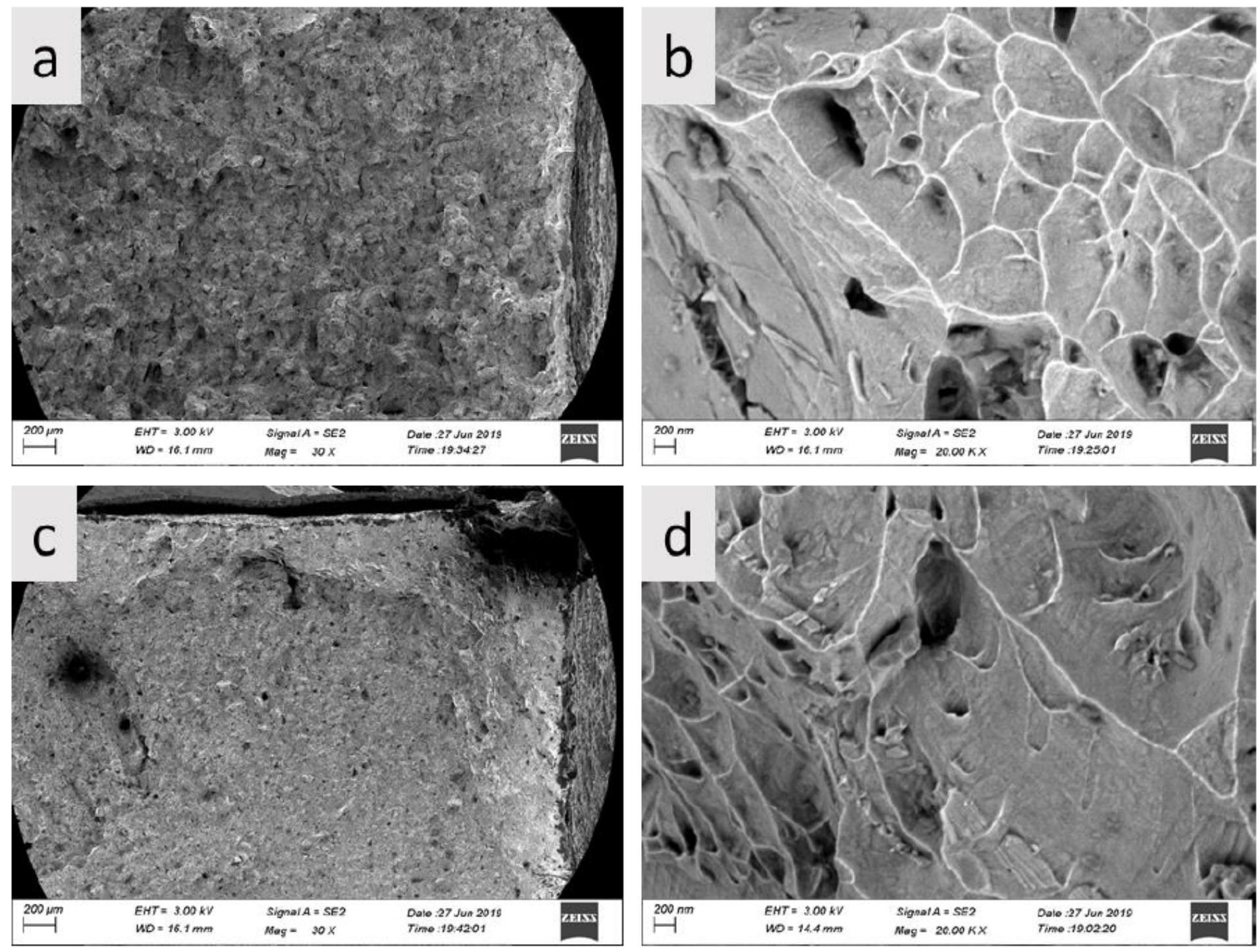

Figure 13

SEM fractography of HT3 IN718. a) X-building direction at 30X magnification. b) X-building direction at 20KX magnification. c) Z-building direction at 30X magnification. d) Z-building direction at 20KX magnification 

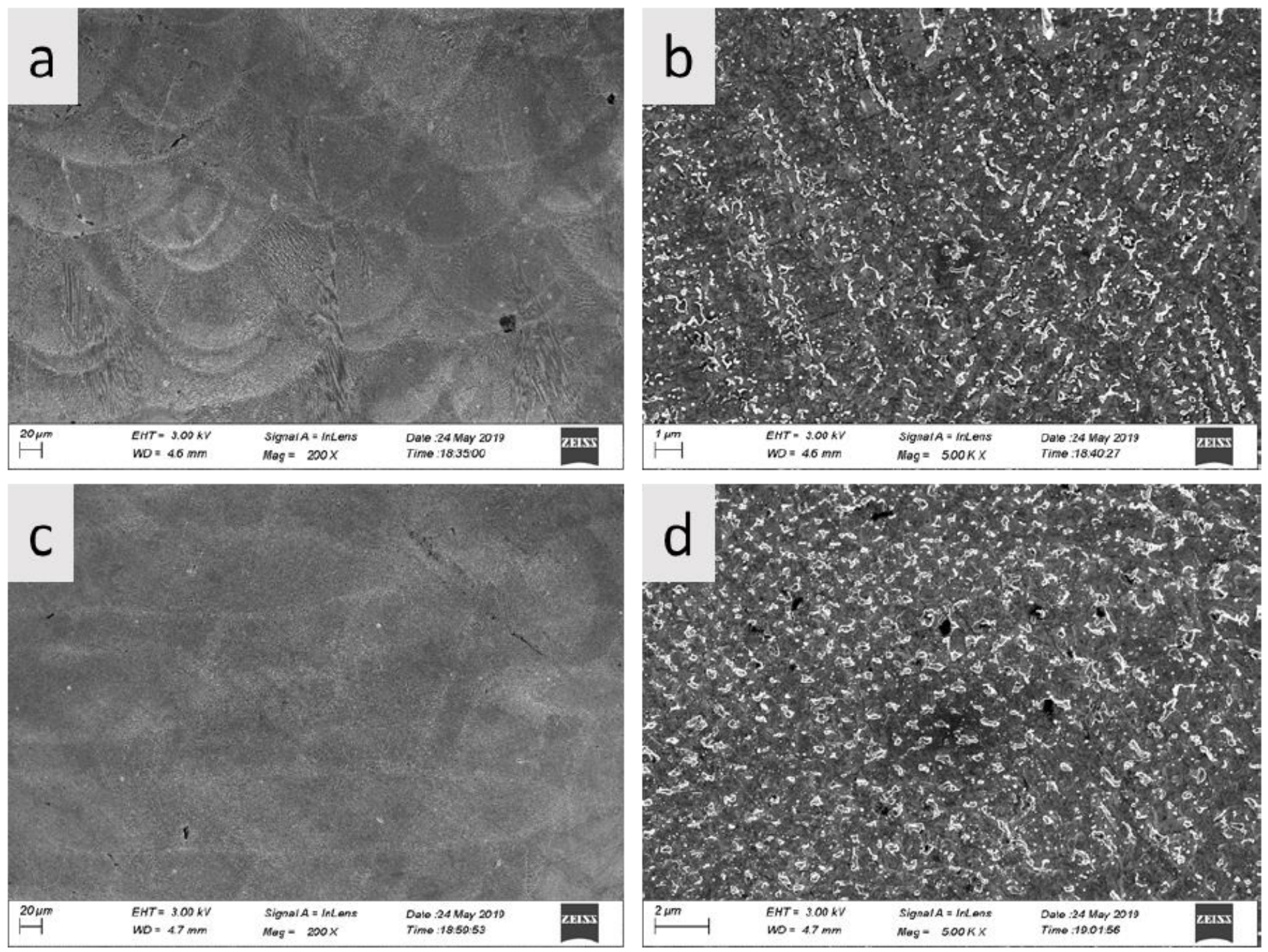

\section{Figure 14}

Microstructure of as-built DMLS IN718 (HT0) imaged on the plane normal to the tensile force. a) X-building direction at 200X magnification, b) X-building direction at 5kX magnification, c) Z-building direction at 200X magnification, d) Zbuilding direction at $5 \mathrm{kX}$ magnification 

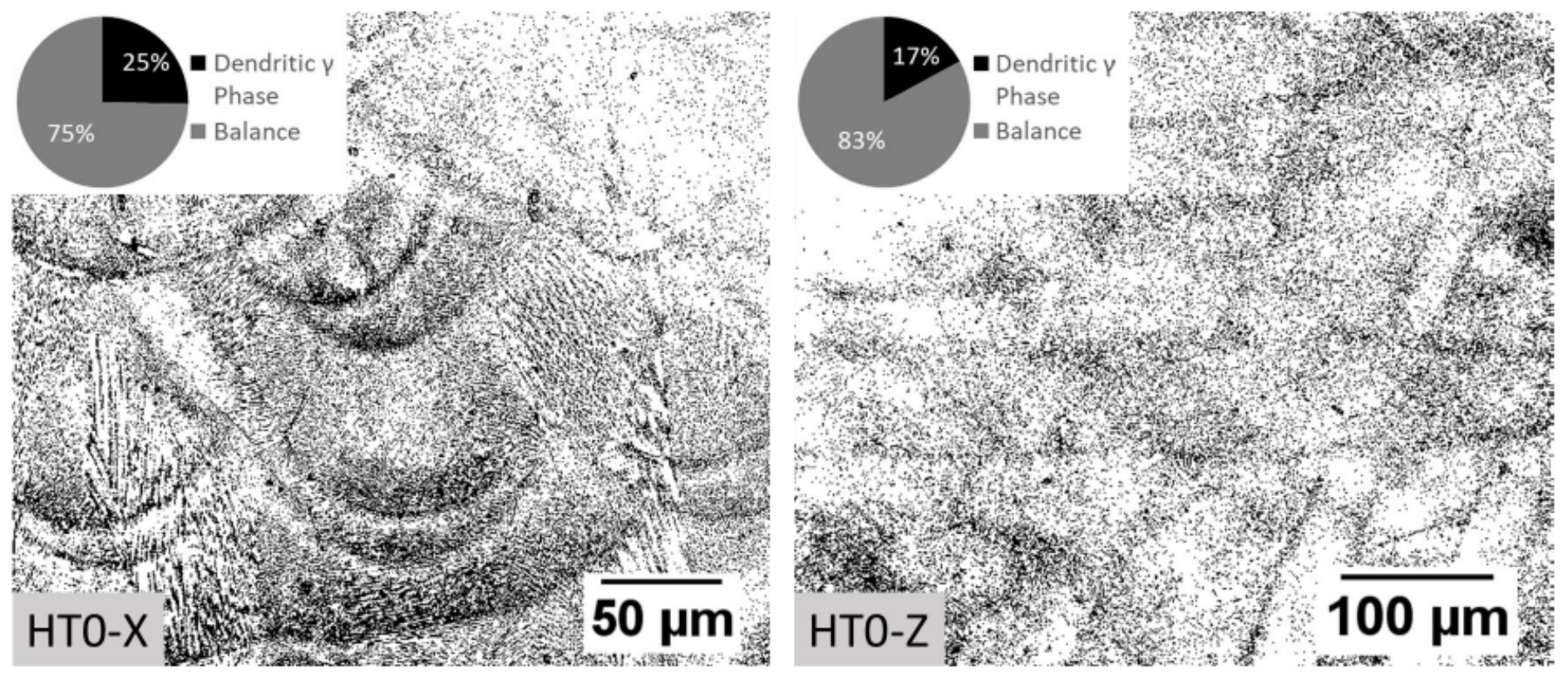

\section{Figure 15}

Thresholded as-built condition microstructure images highlighting the dendritic Y phase, left X-orientation and right Zorientation 

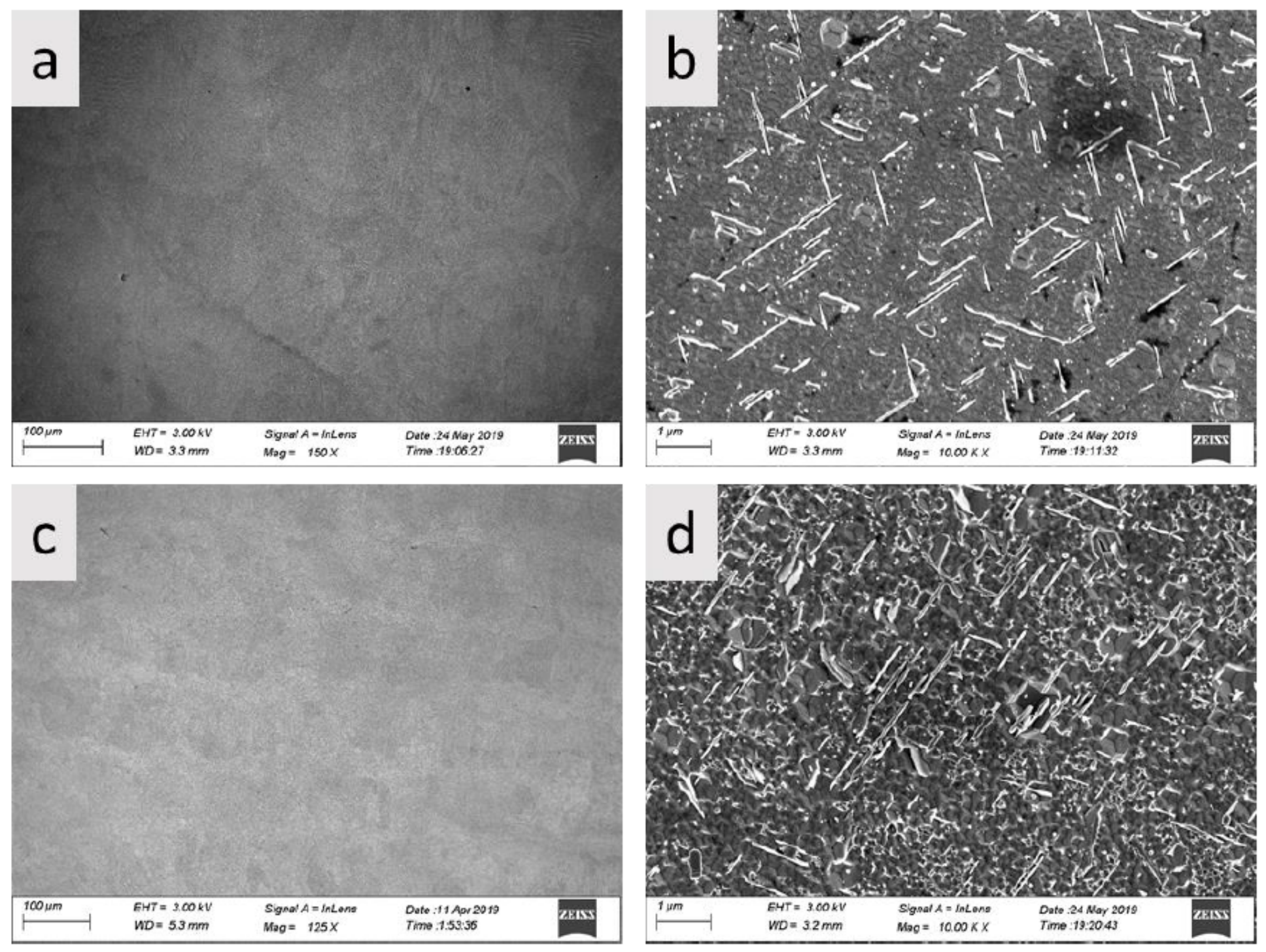

Figure 16

Microstructure of HT1 of DMLS IN718 imaged on the plane normal to the tensile force. a) X-building direction at 150X magnification, b) X-building direction at 10kX magnification, c) Z-building direction at 125X magnification, d) Zbuilding direction at $10 \mathrm{kX}$ magnification 

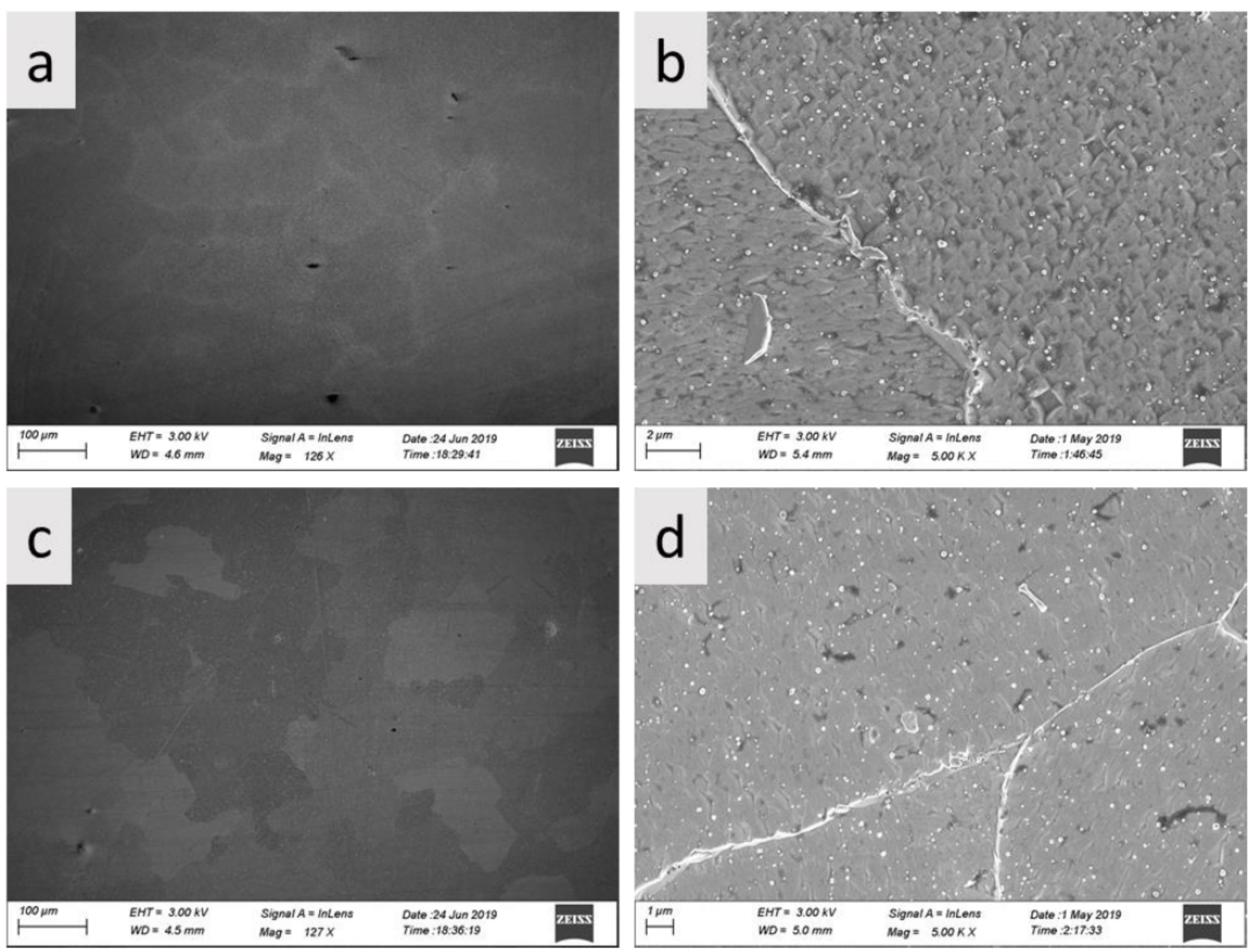

\section{Figure 17}

Microstructure of HT2 of DMLS IN718 imaged on the plane normal to the tensile force. a) X-building direction at $125 X$ magnification, b) X-building direction at 5kX magnification, c) Z-building direction at 127X magnification, d) Z-building direction at $5 \mathrm{kX}$ magnification 



\section{Figure 18}

Microstructure of HT3 of DMLS IN718 imaged on the plane normal to the tensile force. a) X-building direction at 125 magnification, b) X-building direction at 5kX magnification, c) Z-building direction at 122X magnification, d) Z-building direction at $5 \mathrm{kX}$ magnification 


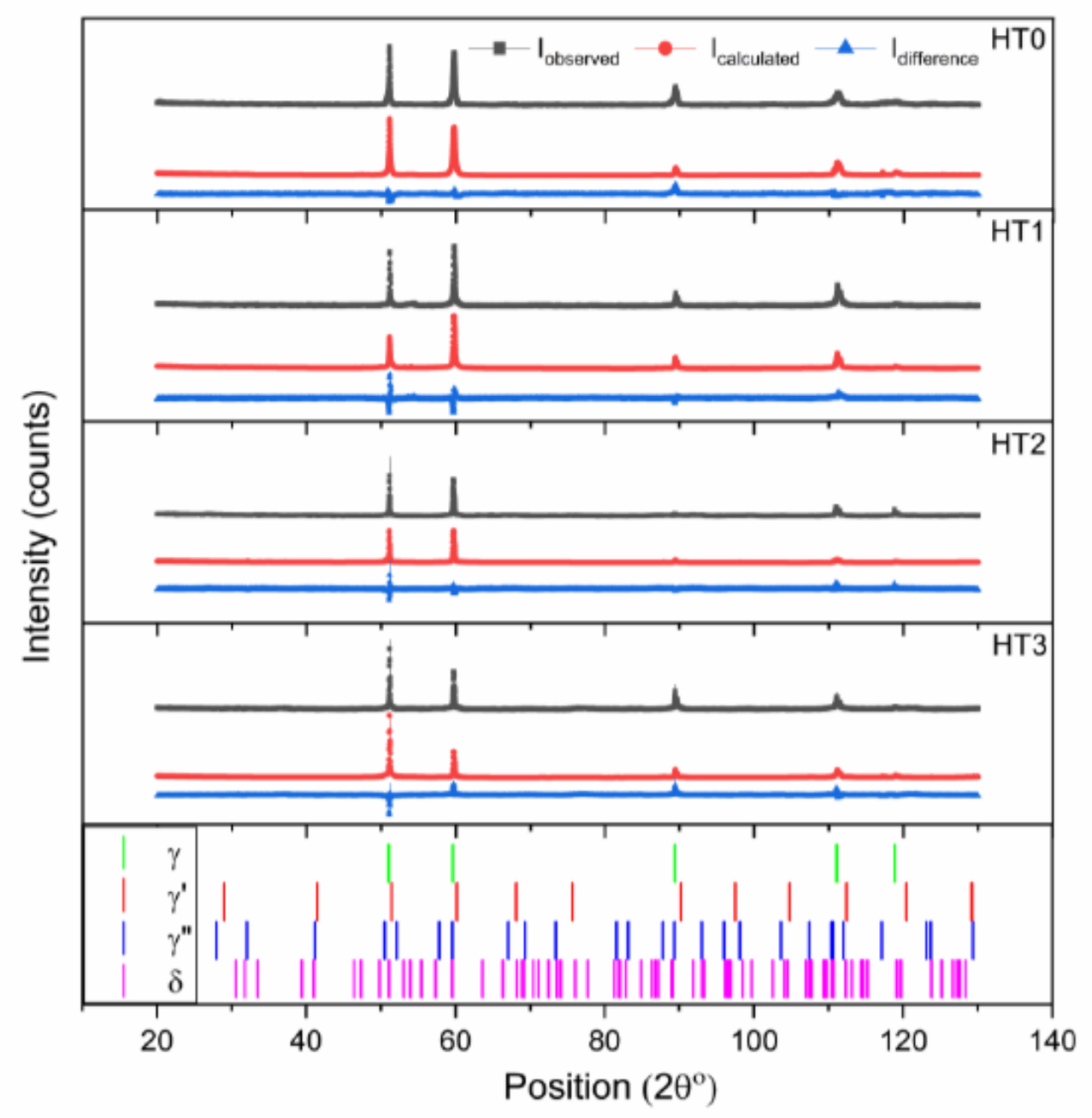

Figure 19

Observed and calculated X-ray data using Rietveld refinement for different heat treatments of IN718 using a Co target with a wavelength of $1.789 \mathrm{~A}^{\circ}$ 


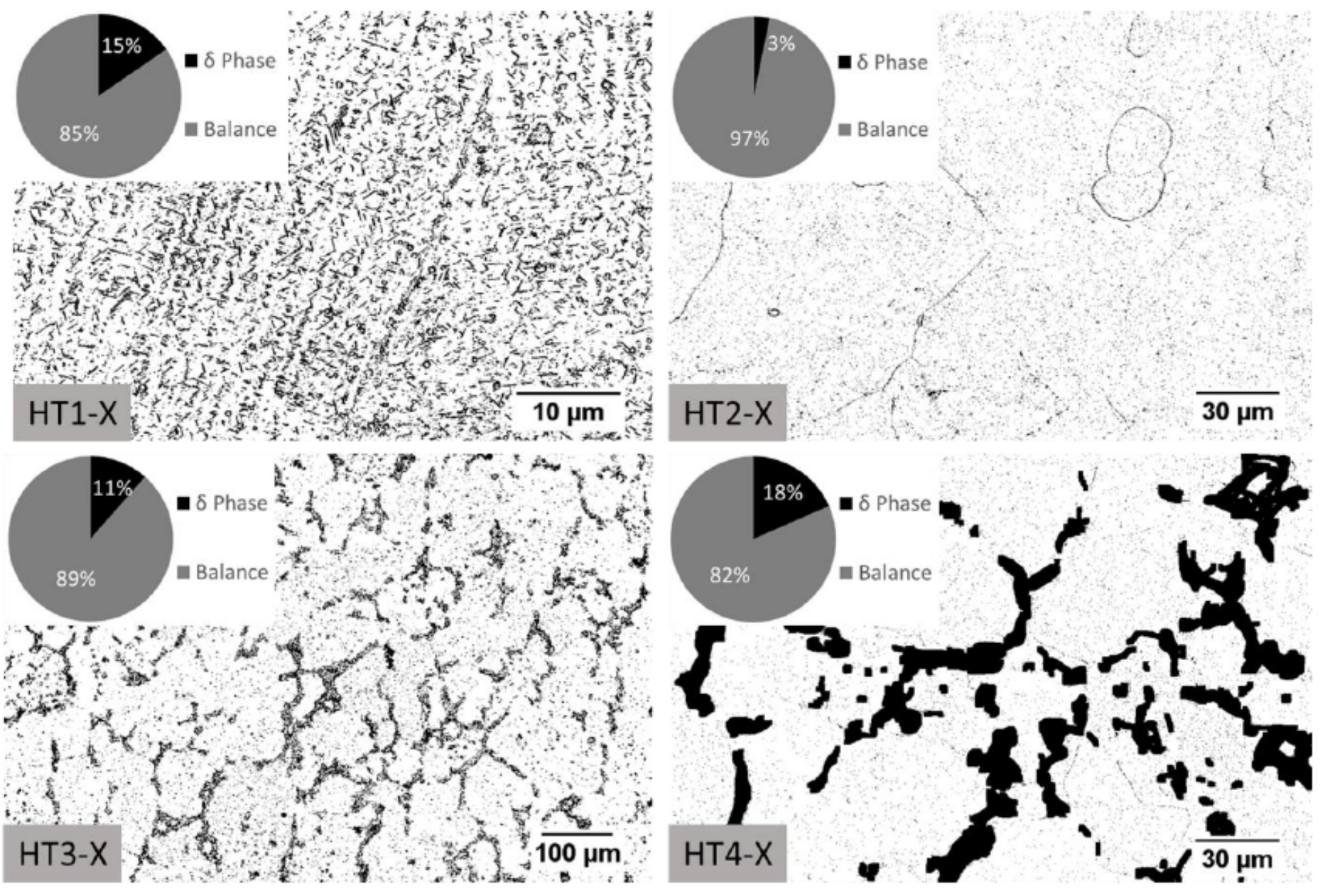

Figure 20

Thresholded SEM microstructure images highlighting the $\delta$ phase plate-like precipitates area fraction in the heat treated specimens

\section{Supplementary Files}

This is a list of supplementary files associated with this preprint. Click to download.

- GraphicalAbstract.png 